\title{
Türkçe Derslerinde Etkileşimsel Kaynak Kullanımı *
}

\author{
Merve AVCI** ${ }^{* *}$ zay KARADAĞ $\breve{G}^{* * *}$
}

• Geliş Tarihi: 26.06.2021 • Kabul Tarihi: 19.11.2021 • Çevrimiçi Yayın Tarihi: 19.11.2021

\section{$\ddot{O} z$}

$\mathrm{Bu}$ çalışmada Türkçenin ana dili olarak öğretiminin yapıldı̆̆ 1 bir sınıfta öğretmenin sınıf içi etkileşimde yararlandığı etkileşimsel kaynaklar ile bu kaynakların işlevlerinin tespit edilmesi amaçlanmıştır. Çalışmada konuşma çözümlemesi yöntemi kullanılmıştır. Çalışma verisi Ankara merkez Etimesgut ilçesinde bir devlet okulundan toplanmıştır. Sınıfa 3 kamera (öğrencileri görecek biçimde öğretmen masasının arkasına ve kapı girişine, öğretmeni görecek şekilde öğrenci sıralarının arkasına) ve 2 ses kayıt cihazı (kameralardan uzak kalan noktalara) yerleştirilmiştir. Toplamda 27 ders saatlik veri kaydedilmiştir. Araştırmada öğretmenin; bekleme süresi kullanma, öğretmen-öğrenci ses yansıması, beden dilinden yararlanma, söz sırası dağıtımında öğrencinin ismini söyleme, geçmiş öğrenme olaylarına gönderim, üstdilsel gönderim/tercih, söylem belirleyici kullanma, öğrenci katkısını şekillendirme, genişletim, vurgu-tonlama, vurgulu olumlu değerlendirme gibi etkileşimsel kaynaklardan yararlandığı görülmüştür. Veri bütüncesinden elde edilen üç kesitte öğretmenin bu kullanımları örneklenmektedir.

Anahtar sözcükler: Türkçe dersi, etkileşimsel kaynak, konuşma çözümlemesi, sınıf içi etkileşim

Atıf:

Avcı, M. ve Karadağ, Ö. (2022). Türkçe derslerinde etkileşimsel kaynak kullanımı.Pamukkale Üniversitesi Ĕ̈itim Fakültesi Dergisi, 55, 1-26. doi:10.9779.pauefd.956084

\footnotetext{
* Bu makale ilk yazarın ikinci yazar danışmanlığında hazırladığı "Vurgulu Olumlu Değerlendirmenin Türkçe Dersleri Sınıf İçi Etkileşiminde Kullanımı" başlıklı yüksek lisans tezinden üretilmiştir.

** Arş. Gör., Hacettepe Üniversitesi, 0000-0002-4007-558X, merve avci@hacettepe.edu.tr

${ }^{* * *}$ Prof. Dr., Hacettepe Üniversitesi, 0000-0003-4596-1203, ozaykaradag@ hacettepe.edu.tr
} 


\section{Giriș}

"İki ya da daha fazla birey arasında karşılıklı paylaşıma dayanan bir iletişim süreci." olarak tanımlanan etkileşim (TÜBA Bilimler Akademisi Türkçe Bilim Terimleri Sözlüğü), toplumsal alanlarda belirli kurallara tabi olarak ortaya çıkar. Kişiler, etkileşim süreçlerinde birbirileriyle olan ilişkilerini bu kurallara uygun biçimde gerçekleştirir; etkileşim içinde ve çeşitli kimlikler kazanır, öğrenir, öğretir sürekli müzakere eder (Sert, 2015). Toplumsal yaşamda kurulan etkileşimler yoluyla hem sosyalleşme sağlanır hem de çeşitli kurumlar var edilir; mahkeme salonları, parlamentolar, okullar ve hatta sınıflar, etkileşim yoluyla sürdürülen kurumlardandır (Sert, 2015).

Toplumsal etkileşimler, kişilerin toplumun bir parçası olarak durum ve zamanlara uygun olarak üstlendiği roller bağlamında şekillenir. Anne-baba-çocuk, hasta-doktor, ev sahibikiracı, öğretmen-öğrenci ilişkileri ve benzerinde üstlenilen roller; çeşitli durum, zaman ve mekânlarda biçimlenen bu rollere örnek gösterilebilir. Örneğin, ev sahibi-kiracı etkileşiminde ev sahibinin evin bakımı için gerekli şeyleri yapması, kiracınınsa kirasını ödemek ve eve zarar vermemek yükümlülükleri arasındadır. Aynı örnekteki kiracının mesleğinin doktor olduğu ve ev sahibinin kendisine muayene olmaya geldiği bir durumda üstlenilecek roller değişiklik gösterecektir. Goffman (2017) bu durumu toplumsal yaşamda davranış kurallarının yükümlülük ve beklentiler odağında gerçekleştiği biçiminde açıklar. Buna göre, toplumsal açıdan oluşan yükümlülükler bireyin belirli ahlaki sınırları gözetmesini gerektirir; beklentiler ise bireyin üstlendiği rolle şekillenen kendisinden beklenen davranış biçimleridir (Goffman, 2017). Sınıf içi etkileşim düzeninde ortaya çıkan etkileşimlerde tanımlanan öğretmen ve öğrenci rolleri, belirli yükümlülük ve beklenti durumlarına örnek gösterilebilir: Öğretmenin bilgi sunması veya keşfedilmesine olanak sağlaması beklenirken öğrencinin söz konusu bilgiyi edinme yükümlülüğü bulunduğu söylenebilir.

Sınıfta öğrenci-öğretmen, öğretmen-öğrenci, öğrenci-öğrenci ve öğrenci-materyal etkileşimi olarak karşımıza çıkan etkileşim, belirli toplumsal roller bağlamında şekillenir. Öğretmen ve öğrenci rolleri de öğretim süreçlerinin planlanması ve uygulanmasında şekillendiricidir. Öğrenme öğretme yaklaşımları bakımından geleneksel kabul edilebilecek sınıflarda öğretmenin baskın olduğu, etkileşimin çoğunlukla öğretmen tarafından yürütüldüğü bir süreç beklenirken modern olarak kabul edilebilecek sınıflarda beklenti, öğrencinin kendi öğrenmesinde aktif rol almasıdır. 
Öğretim programları, öğrenme-öğretme sürecinin tümü üzerinde etkilidir. Öğretim yaklaşımları, materyaller, eğitim ortamı tasarımları, uygulama aşaması vb. tüm unsurlar, öğretim programlarının çizdiği çerçeve içinde belirlenir. Sınıf içindeki etkileşimi de programların temel aldığı yaklaşım biçimlendirir. Türkiye'de 2005-2006 yı1larında yapılan program değişiklikleriyle sınıf içi etkileşimi arttıracak bir öğrenme öğretme yaklaşımı benimsenmiştir (MEB, 2006). Öğrenme hedeflerinin kazanım olarak belirlenmesi sınıf içinde öğrenci rolünü aktif katılımcı olarak belirlemektedir. Temel dil becerilerinin geliştirilmesinde öğrencinin bu özellikleri sergileyebileceği etkinlik ve aktivitelerin kullanılması öngörülmektedir. Sınıf içindeki öğrenme öğretme yaklaşımlarının gerektirdiği öğretmen rolüne göre öğretmenin işi, öğrencilerin yeni bilgileri var olanlarla ilişkilendirmesine ve anlamlandırmasına yardımcı olmaktır (Scales, 2015, s. 39). Öğrenme sürecinde öğretmenin, öğrencinin öğrenmesine yardımcı olması, öğrencilerin birbirileriyle etkileşime geçmesine ve akran öğrenmesine olanak sağlayacak bir öğrenme ortamı tasarlaması beklenmektedir. Öğrencilerin etkinlikler aracılığıyla bir etkileşim sürecinin içine girmesi ve bu yolla sınıf içinde aktif bir rol alması hedeflenmektedir. $\mathrm{Bu}$ nedenle ders işleme sürecinde kullanılan etkinliklerin sınıf içinde öğrencinin daha aktif bir rol almasını beraberinde getirecek nitelikte olması gerekmektedir. Öğretim uygulamaları üzerinde son derece belirleyici olan bu rolleri ve etkilerini görmek, sınıf içi etkileşimi incelemekle mümkündür.

Örgün eğitimde sınıf, dil öğretiminin gerçekleştiği ortam olmasına rağmen sınıfta gerçekleşen süreçlere dair bilgi, sınırlıdır (van Lier, 1988). Öğrenme ortamlarının düzenlenişi, öğrenmenin gerçekleşmesi üzerinde etkiye sahiptir. Van Lier (1988), “öğretme”nin tek başına öğrenmenin gerçekleşmesini sağlayamayacağı; öğrenmeyi sağlayan ya da öğrenmeye ket vuran şartları ortaya çıkarabileceğini ifade etmiştir (s. 32). Bununla birlikte sınıfta gerçekleştirilen çalışmalara dair gerekçelendirmesinde sınıfta neler olup bittiğine ilişkin bilginin sınırlı olduğunu ve bu bilgiyi arttırmanın gerekli ve değerli olduğunu ifade etmiş, bunu sağlamanın sınıftan elde edilen veriyle mümkün olduğunu söylemiştir (van Lier, 1988, s. 37). Ayrıca sınıftan elde edilen verinin sınıf bağlamından hareketle yorumlanabileceğini, bu bağlamın yalnızca dilsel ve bilişsel bakımdan değil, sosyal bağlam bakımından da elzem olduğunu ifade etmiştir (van Lier, 1988, s. 37). Mehan (1979) da sınıf düzenini anlamanın "sınıf”ın tamamını ele alan bütünsel bir yaklaşımla görülebileceğini belirtmiştir. Dil sınıflarındaki sosyal ve pedagojik süreçlerin öğrenmeye etkisinin incelenmesi etkileşim bağlamının incelenmesiyle mümkündür (Sert, 2015). Öğretmen ve öğrenciler pedagojik hedefleri yüz yüze sınıf diyaloğu aracılığıyla iletir ve öğrenmeyi eyleme geçiren de bu 
etkileşimin kendisidir (Huth, 2011). Sınıf ortamında katılımcılar, etkileşimler yoluyla ortak anlam oluşturur, sınıf söylemi incelenerek bu ortak anlam ve sınıf diyaloğunun işlerliği saptanabilir (Mercer, 2008).

Türkçe derslerine ilişkin sınıf içi etkileşime odaklanan çalışmaların sayısı son derece sınırlıdır. Bu çalışmaların bir kısmı sınıf söylemine odaklanmış (Çakır, 2017; Çakır-Sarı, 2020; Özcan ve Aksan, 2017), sınıf etkileşiminin belli bir parçasını (örneğin dönüt) ele almış (Karatay, Dolunay ve Savaş, 2014), kimi çalışmalar da Türkçenin yabancı dil olarak öğretiminde belli bağlamların incelenmesi üzerine (Çimenli ve Sert, 2017; Sumruk, 2019) yapılmıştır. Öte yandan yurt dışında yapılan çalışmalar incelendiğinde sınıf içi etkileşimi mikroanalitik bir bakış açısıyla inceleyen çok sayıda çalışma olduğu görülmektedir. Hem ana dili öğretimi bağlamlarında hem de yabancı dil/ikinci dil öğretimi bağlamlarında yapılan çalışmalar mevcuttur. Bu çalışmalar arasında, öğrencilerin sözel olarak belirtmedikleri ancak anlamakta güçlük çektikleri söz sıralarında öğretmenlerin yapmış olduğu onarımlara odaklanan (Badem-Korkmaz ve Balaman, 2020), ikinci dil öğretiminde üçüncü söz sırasının öğrenme firsatına olanak sağlayabilecek biçimde kullanımını örnekleyen (Girgin ve Brandt, 2019), yabancı dil öğretim bağlamında geçmiş öğrenme olaylarından sınıf içi etkileşimde yararlanmayı örnekleyen (Can-Daşkın, 2017; Can-Daşkın ve Hatipoğlu, 2019), öğretmenin öğrenci yanıtlarını şekillendirme yoluyla pedagojik hedeflere ulaşmayı hedefleyen (CanDaşkın, 2015), olumlu değerlendirmenin kullanımına odaklanan (Batlle, 2021; Fagan, 2014; Waring, 2008; Wong ve Waring, 2009), sesli okuma çalışmalarının sınıf içi etkileşim düzenindeki etkisini inceleyen (Tainio \& Slotte, 2017), vurgu ve tonlamanın sınıf içi etkileşimde kullanımını inceleyen (Hellerman, 2003), diller arası aktarımın iletişim kurma ve bu süreçte katılımı sağlama bağlamında ele alan (Kirsh \& Scale, 2020) çalışmalar bulunmaktadır.

Sınıf içi etkileşimin incelenmesinde, öğretmenin ders konusuyla ilgili kavramsal alanı öğrenciler açısında erişilebilir hâle getirmek için etkileşimsel kaynaklardan nasıl yararlandığını gözlemek, konuşma çözümlemesi yöntemi gibi doğal veriye dayalı bir yöntem aracılığıyla gerçekleştirilebilir (Kääntä, 2021). Sınıf içi etkileşimde genellikle öğretmen konuyu başlatır, geliştirir ve kapatır, dolayısıyla etkileşimi yöneten kişi olarak öğretmenin öğretime dair varsayımları, hedefleri, endişeleri etkileşimi şekillendirir (Lee, 2021). Dil öğreticilerinin, öğretim uygulamalarını planlarken dil öğretiminin sosyal boyutuna da dikkat etmesi gerekmektedir (Leslie, 2017). Öğretim uygulamalarını gözlemlemek ve incelemek, hem ana dil öğretimi bağlamında hem de ikinci dil/yabancı dil öğretimi bağlamlarında dil 
öğretimine dair içgörü sağlar (Kääntä, 2021). Öğrenme ve öğretme yalnızca sözel unsurlarla gerçekleştirilmez, dil dışı unsurlar da anlam ve bağlam oluşturmada kullanılır. Tüm bunları incelemek, özellikle dil sınıflarında, dilin nasıl öğrenildiğinin anlaşılması için gereklidir (Kääntä, 2021).

Türkçe derslerinde sınıf ortamına bütüncül olarak bakılması öğretim uygulamalarının "neliğgi” ve "ne işe yaradığı”" hakkında bilgi sunması açısından önem arz eder. Bu çalışmanın amacı, Türkçe dersleri sınıf içi etkileşiminde öğretmenin etkileşimsel kaynaklardan yararlanma biçimlerini konuşma çözümlemesi yönteminin mikro analitik bakış açısından yararlanarak ortaya koymaktır.

\section{Yöntem}

Çalışmada, konuşma çözümlemesi yöntemi kullanılmıştır. Konuşma çözümlemesi temelinde etnometodolojik bir bakış açısı taşımaktadır. Etnometodoloji, üyelerin toplumsal yaşamdaki yapıp etmelerini kendi süreçleri içinde değerlendirmeyi esas alır (Coulon, 2015). Konuşma çözümlemesi yöntemi verinin analizinde verinin kendisinden yola çıkar. Etkileşimdekonuşmaların düzeni ve etkileşimde-konuşma düzeninde gerçekleşen sosyal eylemleri inceleyen konuşma çözümlemesi, insanların doğal etkileşim sürecinde birbirilerini nasıl anladıklarını nesnel biçimde ortaya koyabilen bir yöntemdir (Sert vd., 2015). Sert ve diğ. (2015), yöntemin ilkelerini şu şekilde sıralamıştır: etkileşim sistematik bir şekilde düzenlenir, etkileşimde katkılar bağlamı şekillendirir ve bağlam tarafından şekillendirilir, çözümleme veriden hareketle yapılır, çözümleme içeriden bir bakış açısı ile gerçekleştirilir (s. 6). Martı (2015) da konuşma çözümlemesinin prensiplerini, "konuşma düzenlidir; konuşmaya katkı birbirini izleyen, ardışık ve o anda oluşturulan yapıdadır, konuşmacılar hem konuşmaya katkıda bulunur hem de bu ardışı yapı sayesinde anlaşılabilir; konuşmanın analizi konuşmanın kendisine dayanır” biçiminde aktarmıştır (s. 269). Sıralanan ilkelerden hareketle konuşma çözümlemesi yöntemi etkileşimde-konuşma düzenini verinin kendisinden hareketle ve düzeni içinde inceler denebilir. Sert ve Seedhouse (2011), analizde tüm ayrıntıların göz önünde bulundurulduğunu ifade etmiş, söz sırası alma ve etkileşimde-konuşmanın konuşma çözümlemesinin temelinde olduğu vurgulamıştır.

Konuşma çözümlemesinde etkileşim, konuşucuların birbirilerine yönelimlerinde ortaya çıkan ayrıntılar ile incelenir; söz sırası alma, onarım, yeğleme gibi etkileşimsel kaynaklar üzerinden değerlendirilir (Sert, vd., 2015). Konuşma çözümlemesi, konuşmanın kendisinden hareketle incelenir, örneğin söz sırası alma ve oluşturma düzeni, konuşucunun kendisinden önceki söz sırasının ardından oluşturduğu söz sırasına ve kendisinden sonra gelen söz sırasına bakılarak 
analiz edilir, bu durum anlama ve anlaşılma göstergesi olarak kabul edilir (Heritage \& Clayman, 2010). Söz sırası alma düzeni; mevcut konuşucunun bir sonraki konuşucuyu sıralı çift kullanımı, bakış veya hitap ile seçmesi veya söz sırasını sonraki konuşucunun kendi kendine alması ile ilerleyebilir (Sacks, Schegeloff ve Jefferson, 1974; akt. Sert vd., 2015). Söz sırası tasarımı ile birlikte dizi düzeni, onarım, yeğleme düzenleri de etkileşimde konuşmanın izlendiği etkileşimsel unsurlar arasındadır. Konuşma çözümlemesi, sınıf düzeni hakkında idealize edilmiş düşüncelerle saptamalarda bulunmak yerine etkileşimin sıralı ve eşzamanlı olarak ortaya çıkmasına odaklanmaktadır (Kimura vd., 2018, s.185). Konuşma çözümlemesi, doğal etkileşimde ortaya çıkan konuşmanın ve sözel olmayan yanlarının, özneler arasılıktan (katılımcıların birbirilerini anlama ve anlaşmada ortaya koyduğu izleklerden) hareketle gözlenmesine ve incelenmesine olanak sağlamaktadır.

\section{Veri Toplama Süreci}

Araştırma için öncelikle Hacettepe Üniversitesi Etik Komisyonu'ndan 23.10.2018 tarihinde izin alınmıştır (Sayı: 35853172-044). Etik komisyon izninin ardından Ankara İl Millî Eğitim Müdürlüğünden gerekli izinler alınmıştır. Bu izinlerin tamamlanmasıyla birlikte çalışma verisinin toplanacağı okul idaresi ile iletişime geçilmiş, idarenin kabulünün ardından öğretmen, veli ve öğrencilerden gönüllü katılım formu alınmıştır. İzinlerin tamamlanması ile birlikte veri toplama aşamasına geçilmiştir. Veri toplama sürecinde Ankara il genelinde 1 günlük kar tatili ilan edilmesi ve yazılı sınav uygulamasından dolayı 3 saatlik kayıt yapılamamış, kalan kayıtlar planlandığı şekilde tamamlanmıştır. 6 haftalık süre diliminde ilk hafta 4 ders saati (117 dakika), ikinci hafta 3 ders saati (103 dakika), 3. hafta 5 ders saati (169 dakika), 4. hafta 5 ders saati (171 dakika), 5. hafta 5 ders saati (179 dakika), 6. hafta 5 ders saati (181 dakika) olmak üzere toplamda 27 ders saati / 920 dakika kayıt elde edilmiştir (Avc1, 2020). Elde edilen veriden seçilen 10 saatlik kayıt, çalışma verisini oluşturmaktadır.

\section{Araştırma Grubu ve Sınıf Ortamı}

Çalışma verisi Ankara merkez Etimesgut ilçesinde bir devlet okulundan toplanmıştır. Söz konusu sınıfa 3 kamera (öğrencileri görecek biçimde öğretmen masasının arkasına ve kapı girişine, öğretmeni görecek şekilde öğrenci sıralarının arkasına) ve 2 ses kayıt cihazı (kameralardan uzak kalan noktalara) yerleştirilmiştir. Türkçenin ana dili olarak öğretiminin gerçekleştirildiği bu sınıfta Türkçe dersi haftalık beş saat olarak işlenmektedir (7. sınıf düzeyi). Türkçe ders kitabı ana materyal olarak kullanılmaktadır. 


\section{Verilerin Analizi}

Analiz aşamasına geçilmeden önce kayıtlar hiçbir odak noktası olmaksızın izlenmiş ve tüm kayıtların ortografik transkriptleri hazırlanmıştır. Odak noktası olarak öğretmenin kullandığ1 etkileşimsel kaynaklar tespit edilmiştir. İlgili etkileşimsel kaynakların öğretmen-öğrenci etkileşimlerinde sıklıkla ortaya çıktığı görülmüş, bu özelliği taşıyan kesitler seçilmiştir. Çalışmada örnek olarak iki kesit ele alınmış, etkileşim düzeni ile birlikte etkileşimsel kaynakların sınıf içi etkileşim süreçlerinde ortaya çıkma yer ve biçimleri açıklanmaya çalışılmıştır.

\section{Bulgular}

Araştırma verisi kapsamında on ders saati içinde öğretmen-öğrenci etkileşimini örnekleyen 48 kesit belirlenmiştir. Söz konusu kesitlerden etkileşimsel kaynak kullanımını temsil eden üç kesit ele alınmış, bu kesitlerde on farklı etkileşimsel kaynağın kırk beş kez kullanıldığ 1 tespit edilmiştir (Tablo 1). Öğretmenin söz konusu etkileşim örneklerinde söz sırası dağıtımını kendisinin yaptığı, öğrencilere yanıtlarını oluşturmak ve düzenlemek için bekleme süresi tanıdığı, etkileşimin seyrini kontrol ve sürekliliğini sağlamak için vurgulu olumlu değerlendirme unsurları ile söylem belirleyicilerden yararlandığı görülmüştür. Bununla birlikte dil bilgisi konularının işlendiği etkileşim örneklerinde üstdilsel gönderimlerden yararlandığı; dil bilgisi yapılarını kasıtlı olarak kullandığı ve vurguladığı örneklere rastlanmıştır.

Tablo 1. Etkileşimsel kaynaklar, işlevleri ve sıklıkları

\begin{tabular}{|c|c|c|c|}
\hline Kesit & Etkileşimsel Kaynak & Kullanım Amacı & Sıklık \\
\hline Kesit & Vurgulu Olumlu Değerlendirme & - Etkinliğin akışını sağlama & 5 \\
\hline \multirow[t]{10}{*}{1} & & - Etkinliği kapatma/diğer & 1 \\
\hline & & etkinliğe geçiş yapma & \\
\hline & Öğretmen-öğrenci ses yansımas1 & - Onaylama & 4 \\
\hline & Beden dilini kullanma & - Sınıf düzenini sağlama & 1 \\
\hline & & - Onay/değerlendirme & 4 \\
\hline & Öğrencinin ismini söyleme & - Söz siras1 verme & 5 \\
\hline & Bekleme süresi & - Öğrenciye yanıtını & 2 \\
\hline & & oluşturmak ya da & \\
\hline & & düzenlemek için zaman & \\
\hline & & tanıma & \\
\hline
\end{tabular}




\begin{tabular}{|c|c|c|c|}
\hline & Söylem belirleyici & - “devam et" anlamı vermek & 2 \\
\hline & & - Onay/değerlendirme & 1 \\
\hline & & - Dikkat çekme & 1 \\
\hline Kesit & Vurgu/tonlama & - Dikkat çekme & 1 \\
\hline 2 & Söylem belirleyici & - Onay/değerlendirme & 2 \\
\hline & Genişletme & - Tamamlama/derinleştirme & 1 \\
\hline & & - Öğgrenci katkısını & 1 \\
\hline & & şekillendirme & \\
\hline & Öğrencinin ismini söyleme & - Söz siras1 verme & 2 \\
\hline & Bekleme süresi & - Öğrenciye yanıtını & 1 \\
\hline & & oluşturmak ya da & \\
\hline & & düzenlemek için zaman & \\
\hline & & tanıma & \\
\hline & Vurgulu Olumlu Değerlendirme & - Etkinliğin akışını sağlama & 1 \\
\hline & Epistemik durum yoklaması & - Ek bilgi talebi & 1 \\
\hline Kesit & Söylem belirleyici & - "devam et" anlamı vermek & 2 \\
\hline 3 & Beden dilini kullanma & - Onay/değerlendirme & 1 \\
\hline & Genişletme & - Ek bilgi talebi & 1 \\
\hline & Öğretmen-öğrenci ses yansımas1 & - Onaylama & 2 \\
\hline & & - Geçiş & 1 \\
\hline & Vurgulu olumlu değerlendirme & - Etkinliği kapatma/diğer & 1 \\
\hline & & etkinliğe geçiş yapma & \\
\hline & Üstdilsel gönderim/tercih & - Bir dil bilgisel yapının & 1 \\
\hline & & kasıtlı olarak kullanımı ya & \\
\hline & & da sorulması aracılı̆̆ıyla & \\
\hline & & öğrenciye sunulan ileti & \\
\hline
\end{tabular}

Kesit1'de ikinci dönemde haftanın ilk dersinin 18. dakikası ile 20. dakikası arasında Türkçe ders kitabında yer alan etkinliklerden birinin yapıldığı etkileşim düzeni örneği verilmektedir. Öncesinde etkinliğin yönergesi, "zaman anlamı taşıyan kelime ve kelime gruplarını bulunuz" ifadesi okunmuş, zaman anlamı taşıyan sözcükle neyin kastedildiği sorusu öğretmen tarafından sorulmuştur. Öğretmen, sorusunun yanıtını "zaman zarfı” olarak 
aldıktan sonra etkinliğe geçmiştir. Kesit 1'in ilk satırı öğretmenin bu yanıtı tekrar edişi ile başlamaktadır.

\section{Kesit $\mathbf{1}^{1}$}

(00.18.14.5-00.20.16.9, Süre: 02.02.6)

01 ÖGRT: $\quad$ zaman zarfinı bulmamızı istiyo

02

03 Ö1: $\quad$ ya kendi söylüyo ...((anlaşılmayan konuşma) $)$

04 ÖGRT: alla:h alla:h ya: $\uparrow$

05 ÖGRT: $\quad$ bakiyim $\downarrow$ Ö3 yapmıştır ondan kopya çekelim + Ö3’ün kitabını alıp

öğretmen masasına koyup bu kitaptan takip ediyor.

06

07 ÖGRT: $\quad$ derken $(0.7) \uparrow \underline{\text { derken }}$

08

09 Ö1: aa:^ Ö3 ödevini yapmamış

10 ÖGRT: $>$ ha:yır $\uparrow$ ödev değildi ki<

11

12

13

14 15

tamam tamam

(1.0) +öğretmen eliyle masaya vuruyor

ÖGRT: >ona bakmiyorum zaten<

şşt

Öğretmenin, yönergede sorgulanan bilgiyi tekrar ettikten sonra ön siradan bir öğrencinin kitabını "Ö3 yapmıştır ondan kopya çekelim” diyerek aldığı görülmektedir. Ö3'ün etkinliği yapmadığını şaşırarak ifade ettikten sonra Ö1, etkinliğin ödev olmadığını söyler, sınıfta oluşan sesten dolayı öğretmen 10. satırda "tamam tamam" diyerek, 11. satırda öğrencilere 1.0 saniyelik bekleme süresi (Rowe, 1984) tanıyıp elini masaya vurarak, 12. satırda ">ona bakmıyorum zaten<" diyerek, 14. satırda "şş" diyerek (Girgin \& Brandt, 2011) ve 13 ile 15. satırlarda kısa süreli beklemelerle sınıfta düzeni yeniden sağlamaya (Burden, 2013) çalışmaktadır.

1 Kesit 1, ilk yazarın ikinci yazar danışmanlığında hazırladığı "Vurgulu Olumlu Değerlendirmenin Türkçe Dersleri Sınıf İçi Etkileşiminde Kullanımı” isimli tezden alınmıştır. 
16 ÖGRT: peki Ö2 $2(0.5)$

17 şu yedinci etkinliği oku bakalım

19 Ö2: aşağıdaki cümlelerde yer alan

20 ÖGRT: [şşst $]($.

21 Ö2: [kelime] ve kelime gruplarını belirleyerek cümleler yazınız (0.3) pardon boşluklara yazınız

Öğretmenin söz sırası dağ1lımını kendisinin yaptı̆̆g görülmektedir. Ö2’ye yükselen bir tonlamayla söz verdikten sonra öğrenciden etkinlik yönergesini okumasını istemektedir. 1.3 saniyelik bir bekleme süresinin ardından Ö2 yönergeyi okurken öğretmen “ [ şşt ] ( . )" diyerek sınıfta düzeni yeniden sağlamaktadır. 23. satırda öğrencinin kendi başlatımlı kendi onarım gerçekleştirerek yönergeyi okumayı tamamladığı görülmektedir.

24 ÖGRT: [peki:]

25 Ö2: [insan]larla iyi geçinirsek ömür boyunca mutlu

$26 \quad$ oluruz (0.5) 11 ömür boyunca diyo

27 ÖGRT: ömür boyunca, zaten örneği yapmış

28 evet (.) devam edelim

29 Ö2: $\quad$ her zaman ölçülü hareket etmek durumundayız

30 (.) $11:(0.9)$ her zaman

31 ÖGRT: ne zaman $\uparrow$ ölçülü hareket [etmek durumundayız

+başıyla onaylayarak

32 Ö2:

[her zaman

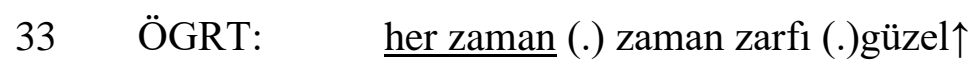

Öğretmenin söylem belirleyici ile öğrencinin devam etmesine onay vermesinin ardından Ö2 örnek cümleyi okumaktadır. 0.5 saniyelik bir bekleme süresinin ardından “ュュ ömür boyunca diyo" diyerek örneği tekrarlamaktadır. Öğretmenin söz grubunu tekrar etmesi ve "zaten örneği yapmış" demesinden sonra söylem belirleyici ile etkileşimi sürdürdüğü görülmektedir. 29. satırda Ö2 sıradaki cümleyi okumaktadır. Kısa bir bekleme 
süresi ve zaman kazanmak üzere çıkarılan sesin ardından "her zaman" cevabını vermektedir. 31. satırda öğretmen, yükselen bir tonlamayla ve yüksek sesle zarfi buldurmaya yönelik olan soruyu söylemekte ardından cümleyi tekrar etmektedir. Öğretmenin tekrarı bitmeden Ö2'nin de cevap verdiği, buna eş olarak öğretmenin başıyla onayladığı görülmektedir. 33. satırda öğretmenin zarfı yeniden vurgulu biçimde söylemekte, kısa bir bekleme süresinin ardından türünü belirtmekte ve öğrenciye yükselen bir tonlamayla vurgulu olumlu değerlendirme yapmaktadır. 0.5 saniyelik bir bekleme süresinin ardından öğretmen söz sırası dağıtımını kendisi yapmakta, Ö3'e ismini söyleyerek söz vermektedir.

35 ÖGRT: $\quad$ Ö3 yap bakalım yapmış benim kuzucum hiç yapmaz mı?

38 Ö3: eve:t $\uparrow$ sabahleyin karşılaştığımız güne günaydın diyor

40 ÖGRT: $\quad$ eve:t (.) ne zaman günaydın diyor muyuz? (.) sabahleyin (.) Ö4?

Öğretmen, etkileşimin başında Ö3'ün kitabını alırken etkinlikleri çözmediğini söylediği kısma atıfta bulunarak "Yapmış benim kuzucum hiç yapmaz mı?" demektedir. Daha sonra öğretmenin söylem belirleyici ile devam edebileceğini göstermesinin ardından Ö3 cümleyi okumakta ve cümlede yer alan zarfı kısa bir duraksamanın ardından söylemektedir. Öğretmen 40. satırda söylem belirleyici ile cevabı onaylamakta ve cümleyi zarfı buldurmaya yönelik soru ile birlikte tekrar etmektedir. Öğretmenin zarfı da yineledikten sonra Ö4'e söz verdiği görülmektedir.

43 Ö4: $\quad$ 11: kişisel-kişisel gelişimle ilgili kitapları

44 geçen yıl okumuştum (.) geçen yıl

45 ÖGRT: $\quad$ ne zaman $\uparrow$ okumuştum[? geçen y]11

+başıyla onaylayarak

46 Ö4: [geçen yıl]

47 ÖGRT: a:ferin (.) Ö5?

48 Ö5: $\quad$ insanlar bahar aylarında daha mutlu oluyor (.)

49 bahar ayları 
50 ÖGRT: ne zaman mutlu oluyor? $\uparrow$

51 Ö5: bahar[aylarında

52 ÖGRT: [bahar aylarında (0.3) aferin

+başıyla onaylayarak

42. satırda görülen 0.5 saniyelik bir bekleme süresinin ardından Ö4 cümleyi okumakta ve kısa bir süre sonra cevabı vurgulu bir biçimde söylemektedir. Öğretmen 45. satırda zarfı buldurmaya yönelik soruyu vurgulu ve yükselen bir tonlamayla söylerken sorusunu tamamlamadan öğrencinin yanıtı tekrar ettiği görülmektedir. Öğretmen, öğrencinin yanıtına “a: ferin” diyerek vurgulu olumlu değerlendirme yapmakta ve etkileşimin sürdürülmesini sağlamaktadır. Öğretmen, Ö4'e verdiği vurgulu olumlu değerlendirmenin ardından söz sırasını ismini söyleyerek Ö5'e vermektedir. Ö5, 48. satırda cümleyi okumakta ve kısa bir duraksamanın ardından 49. satırda "bahar ayları" cevabını vermektedir. Öğretmen, zarfı buldurmaya yönelik soruyu vurgulu ve yükselen bir tonlamayla tekrar etmektedir. Ö5'in öğretmenin sorusuyla birlikte cevabını tekrar etmeye başladığı ve öğretmenin de Ö 5'in bu katkısını hem sözel olarak (cevabın tekrarı yoluyla) hem de beden hareketleriyle onayladığı görülmektedir. Kısa bir duraksamanın ardından da öğretmen vurgulu olumlu değerlendirme vererek etkileşimi devam ettirmektedir.

56 Ö6: sanatçı lise yıllarında uluslararası bir yarışmaya katılmış (.) lise yıllarında $\downarrow$

58 ÖGRT: ne zaman yarışmaya katılmış + başıyla onaylayarak 59 li[se yıllarında (0.3)

60 Ö6: $\quad{ }^{\circ}\left[\right.$ lise yıllarında ${ }^{\circ}$

61 ÖGRT: (0.3) a:ferin

0.5 saniyelik bir bekleme süresinin ardından Ö6'ya ismini söyleyerek söz vermektedir. 55. satırda gözlenen 0.6 saniyelik bekleme süresinin ardından Ö6 cümleyi okumakta ve kısa

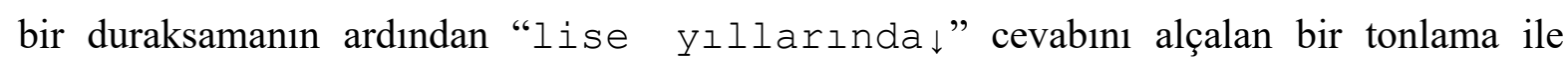
vermektedir. Öğretmen yeniden zarfı buldurmaya yönelik soruyu vurgulu biçimde sesletirken başıyla öğrenci cevabını da onaylamakta ve cevabı tekrar etmektedir. Ö6'nın da öğretmenin 
tekrarını örtüşme içinde kısık sesle tekrar ettiği gözlenmektedir. 0.3 saniyelik kısa bir bekleme süresinin ardından öğretmen vurgulu olumlu değerlendirme ile etkileşimi sürdürmektedir.

62

63

64

65 Ö7:

66

67

$68 x$

69 ÖGRT:

70
Ö7?

çoğu zaman en büyük pişmanlıklarımız

birbirimize söylediklerimizden kaynaklanır (.)

[çoğu ]zaman

[çoğu ] ((hangi öğrenci tarafından söylendiği anlaşılamadı))

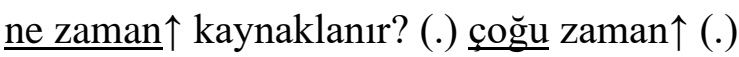

a:ferin

62. satırda görülen 0.9 saniyelik bir bekleme süresinin ardından öğretmen Ö7’ye ismini söyleyerek söz sırası vermektedir. 0.8 saniyelik bir bekleme süresinin ardından Ö7'nin cümleyi okuduğu görülmektedir. Kısa bir bekleme süresinin ardından Ö7 cevabı söylerken aynı zamanda bir başka öğrencinin de "[çoğu ]" diyerek söz girdiği ancak sonrasında sustuğu görülmektedir. Öğretmen, zarfı buldurmaya yönelik soruyu vurgu ve yükselen tonlama ile söylemekte ve cevabı tekrar etmektedir. 70. satırda öğretmenin vurgulu olumlu değerlendirme yaptığı 71. satırda da söylem belirleyici ile sonraki soruya geçişi vurguladığ görülmektedir.

72 Ö8:

73

74 ÖGRT:

75 Ö9:

80 ÖGRT:

81 Ö9:

82 ÖGRT:

83

84 evet $\uparrow$ Ö8?

iletişim konulu konferansa iki gün sonra

gideceğiz (.) iki gün sonra

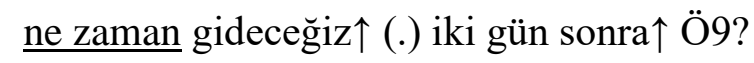

bin dokuz yüz seksen sekiz bin dokuz yüz

doksan sekiz yılları arasında üniversitede

öğretim görevlisi olarak çalıştım (.) >bin

dokuz yüz seksen sekiz bin dokuz yüz doksan

sekiz $<$ yılları $\downarrow$

ylları ara[sinda (.) dimi?

[arasinda $\downarrow$

ne zaman çalışıı (.) şu şu şu yıllar

arasında $\uparrow$ arasındayı da alıyoruz (.) $>$ aferin $<$

şimdi个 (1.0) 11: (.) Ö10个 
Ö8'e ismini söyleyerek söz vermesinden sonra Ö8 cümleyi okumakta ve cevab1 vermektedir. Öğretmenin bu katkıdan sonra da yine zarfı buldurmaya yönelik soruyu tekrar ettiği görülmektedir. Cevabı da yükselen bir tonlama ile tekrar eden öğretmen Ö9'a ismini söyleyerek söz vermektedir. Ö9, cümleyi okuduktan sonra cevabı hızlı bir biçimde ">bin dokuz yüz seksen sekiz bin dokuz yüz doksan sekiz< yılları $\downarrow$ şeklinde vermektedir. Öğretmen Ö9'un cevabını alırken cevabın son kısmı olan “yılları ara[sında (.)” y1 tekrar etmektedir. Ö9 da öğretmenin tekrarı ile örtüşme içinde “ $\quad$ [arasında $\downarrow$ ” olarak bitirdiği cevabına “[arasında $\downarrow$ ” sözcüğünü de eklemektedir. Öğretmenin, Ö9’un yapmış olduğu hatayı 80. satırda örtük biçimde; 82-83. satırlarda ise açık biçimde düzelttiği görülmektedir. Ardından vurgulu olumlu değerlendirme veren öğretmen etkileşimi sonlandırmakta ve 84 . satırda "şimdi $\uparrow$ " ifadesi ve vurgulaması ile bir başka öğrenciye söz vermesiyle sonraki etkinliğe geçiş yapmaktadır.

Öğretmen-öğrenci etkileşiminin örneklendiği kesitte Türkçe ders kitabında yer alan bir dil bilgisi etkinliğinin işlendiği görülmektedir. Bu etkinliğin yapıldığı etkileşim sürecinde öğretmenin söz sırası dağıtımını yaptığı, öğrencilere yanıtlarını oluşturmaları için bekleme süresi tanıdığg, öğretmen-öğrenci ses yansımasını kullanarak öğrenci yanıtlarını tekrar etme yoluyla onayladığı, beden dilini ve yönelimi kullandığı, sınıfta düzeni sağlama adına çeşitli unsurlardan yararlandığı, vurgulu olumlu değerlendirme unsurlarını kullandığı görülmektedir.

\section{Kesit 2}

Kesit2'de etkileşim örneğinin ders kitabında yer alan metinlerden biri üzerine gerçekleştiği görülmektedir. Etkinlikte Türk kahvesi ile ilgili bir metin okunurken öğretmenin okuyan öğrenciyi durdurduğu ve Türk kahvesi ile ilgili metinde geçen bilgileri yanıtı bilinen soru ile sorduğu görülmektedir. 2. satırda öğrencilerin dikkatini çekmek için yükselen bir tonlama kullanmaktadır. Bu esnada Ö28, durumla ilgili bir yorum yapmıştır. Öğretmen bu yorumu 4. satırda onaylayarak sorduğu bilgiyi kendisi tamamlamaktadır (4.-9. satır). 10. satırda Ö5 isimli öğrenci, öğretmenin “şey olabilir ama zehirli olsalar keçiler ölürdü dimi?” çıkarımını "belki keçileri etkilemiyo" şeklinde yanıtlamaktadır. Öğretmenin bu yanıtı da söylem belirleyici ile onayladıktan sonra öğrenci yanıtını kavramsallaştırarak "yani risk almış çoban kendi de denemiş bunu (.)"dediği görülmektedir.

01 ÖGRT: dur önce bir çoban kendi sürüsünde bunu fark ediyor dimi? (.)

02 daha önce (.) daha önce $\uparrow$

03 Ö28: onu fark etmesi de başarı ama 
04 ÖGRT: evet çok önemli (.) daha önce kahve nedir bilen yok, dimi e bu çoban ee işte keçilerinin mi 11 bu otları-yaprakları yediğini görüyo ve daha az uyanık 11-yok daha fazla uyanık kaldıklarını daha az uyuduklarını fark edip dinç olduklarını görüyo ve kendisi de deniyo o da bi cesaret mesela zehirli bi şey olabilir ama zehirli olsalar keçiler ölürdü dimi?

10 Ö5: belki keçileri etkilemiyo

11 ÖGRT: evet beli dimi yani risk almış çoban kendi de denemiş bunu (.)

12 sonra yayılıyo bu şekilde

13 çekirdeklerini pişiriyolarmış dimi

14 Ö28: valla --- ((anlaşılamayan konuşma))

15 ÖGRT: dimi? çekirdeklerini çekirdeklerini işte kırmızı çekirdekleri

16 alıp kurutarak sonra onları çekerek döverek öğüterek dimi (.)

17 kahve haline getirilmiş

18 11: bir sürü kahve çeşidi var günümüzde önceden Türk kahvesi-

19 >ama neden Türk kahvesi denmiş (.) bu da ilginç<

13. satırda öğretmenin kahve ile ilgili bir başka bilgiye geçtiği görülmektedir. 13.-17. satırlar arasında bu özellik hakkında bilgiyi derinleştirdikten sonra 18. satırda Türk kahvesi denmesinin sebebini sorduğu soruyu kendi başlatımlı kendi onarımla 19. satırda hızlı biçimde tamamlamaktadır. Bu soruya yanıt olarak 20. satırda Ö11 isimli “çünkü tadı daha acı" yorumunu yapmaktadır. Öğretmenin bu yorumu karşılıksız bıraktı̆̆ı, sorusunu genişleterek yinelediği görülmektedir.

20 Ö11: çünkü tadı daha acı

21 ÖGRT: $\quad$ yani Türkiye'de, şunu hiç düşündünüz mü, Türkiye'de

22 yetiştirilmediği halde Türk kahvesi deniyo

23 Ö28: çok seviyoruz

24 ÖGRT: acaba neden? Ö7?

25 Ö7: hocam Osmanlı

26 ÖGRT: bi dakka (.)

27 Ö7: o zaman osmanlı topraklarında Arap yarımadasından gelen bi

28 madde olduğu için ve orda yetiştiği için sonra saray

29 getirilmiş sonra Osmanlı (anlaşıılmayan konuşma) 
30 ÖGRT: tamam da neden Arap kahvesi denmemiş

23. satırda Ö28'den gelen "çok seviyoruz" yanıtını da yeğlenen yanıt olarak kabul etmeyen öğretmenin sorusunu “acaba neden? Ö7?” şeklinde yinelediği ve Ö7 isimli öğrenciye ismini söyleyerek (Mehan, 1979) söz verdiği görülmektedir. 27-29. satırlar arasında Ö7'nin soruyu yanıtladığı ancak öğretmenin bu cevabı da yeğlenen yanıt olarak işaret etmediği görülmektedir (30. satır). 31. satırda Ö27'nin parmak kaldırıp “hocam hocam (.) ben biliyorum" diyerek yanıtlamaya gönüllü olduğunu (Kardaş-İşler, 2019) göstermekte, öğretmen de sorusunu tamamladıktan sonra ismini söyleyerek ona söz vermektedir.

31 Ö27: hocam hocam (.) ben biliyorum \#parmak kaldırıp

32 ÖGRT: veya başka bi ülke denmemiş de Türk kahvesi denmiş? Ö27?

33 hişşt (.) bi dakka çok önemli,

$34 \quad(6.3)$

35 Ö27: Türklerin

$36 \mathrm{x}$ : babası tarihçi ((hangi öğrenci tarafından söylendiği anlaşılamadı))

37 ÖGRT: dur (.) Ö27 baba torpilli

38 bi dakka

39 Ö27: hocam çünkü Türkler kahveyi alıp farklı bi şekilde pişirmiş

40 normal Araplar Lübnanlılar gibi değil farklı şekilde pişirmiş

41 dibinde telvesi bi şeyi kalmış o yüzden

42 ÖGRT: $\quad$ hıh (.) güzel ve bunu törenle mi yapmışlar tören haline mi

43 getirmişler?

33. satırda öğretmenin sınıfta düzeni sağlamaya (restoring order, Burden, 2013) çalıştığ1 görülmektedir. 6.3 saniyelik bir bekleme süresinin ardından Ö27'nin yanıtına başladığı ancak öğretmenin yeniden durdurarak sınıf düzenini sağladığı görülmektedir. 36. satırda bir başka öğrencinin Ö27'nin babasının Tarih öğretmeni oluşunu işaret ettiği, öğretmenin de 37. satırda bu yorumu sürdürdüğü görülmektedir. 38. satırda öğretmen yeniden dikkat çekmekte, 39-41. satırlar arasında Ö27'nin yanıtını tamamladığı görülmektedir. Öğretmen "hıh (.) güzel” diyerek onaylamakta, vurgulu olumlu değerlendirme ile yanıtı değerlendirmektedir. Bunun hemen ardından ek bir soru ile öğrenci yanıtını şekillendirmektedir (shaping learner contribution, Can-Daşkın, 2015). 


\section{Kesit 3}

01 Ö11: ben yapiyim mi

02 ÖGRT: $\quad$ sekizinci soruya bakın $\uparrow$ peki Ö11 oku bakalım ne diyo

03 Ö11: aşağıdaki cümlelerde pekiştirilmiş sözcüklerden hangisi zarf

04 görevinde kullanılmıştır?

05 ÖGRT: ha

06 Ö11: a sapasağlam vazoyu niye çöpe attın

07 ÖGRT: dur. sapasağlam sözü sözcüğü pekiştirilmiş bir sözcük mü?

08 Ö11: evet

09 ÖGRT: $\quad$ sapsağlam araya ünlü girmiş sapasağlam olmuş düşebiliyodu veya 10 araya ünlü girebiliyodu bunu anlatmıştık. peki zarf görevinde 11 kullanılanı soruyo, sapasağlam vazo demiş (.)

12 Ö11: sifat

13 ÖGRT: $\quad$ sifat dimi, nasıl vazo sapasağlam vazo

14 ismi etkilemiş sıfat görevinde

15 b ye bakalım

16 Ö11: güpegündüz soymuşlar dükkanı

17 ÖGRT: ha

18 Ö11: ne zaman soymuşlar güpegündüz soymuşlar burda zarf.

19 ÖGRT: $\quad$ zarf dimi, soymak fiildir, çekimli fiil. ne zaman soymuşlar, 20 güpegündüz (.) hangi zarf? (.) hangi tür?

21 Ö11: zaman zarfi

22 ÖGRT: zaman zarfi

23 c ye bakalım yine

24 Ö11: dümdüz bi yol çıkmıştı karşımıza, dümdüz bi yol, nasıl bir yol 25 dümdüz bir yol, burda sıfat

26 ÖGRT: sifat, aferin

27 Ö11: masmavi gökyüzü huzur vermişti (.) nasıl gökyüzü, masmavi

28 gökyüzü burda da sifat

29 ÖGRT: $\quad$ a:ferin (.) ismi etkilediği için sıfat

Kesit 3, öz seçimli öğrenci başlatımı ile başlamaktadır. Ö11 söz istedikten sonra öğretmen, tüm sınıfın dikkatini yükselen bir tonlama kullanarak çekmektedir. Daha sonra söylem belirleyici kullanarak sözü yeniden öğrenciye vermektedir. Öğrenci yönergeyi 
okuduktan sonra "ha" diyerek devam etmesini sağlamıştır. İlk seçeneği okuyan öğrenciyi durdurduktan sonra yönergede yoklanan bilgiyi seçenekte "sapasağlam sözü sözcüğü pekiştirilmiş bir sözcük mü?” diyerek sorgulamaktadır. Öğrenciden evet yanıtını aldıktan sonra başıyla onaylayarak sapasağlam sözcügünün pekiştirme yolunu geçmiş öğrenme olayına gönderme (Can-Daşkın, 2017; Can-Daşkın, Hatipoğlu, 2019) ile açıklamaktadır. Açıklamanın ardından yönergede istenen bilgiyi ve cümlede geçen pekiştirilmiş sözcüğü yanındaki sözcükle birlikte tekrarlayarak öğrenciden yanıt beklemektedir. Aynı zamanda sözcükte gerçekleşen ses olayına da vurgu yapmaktadır. Öğretmen, tekrar yoluyla sorgulanan bilgi için gerekli incelemenin sapasağlam ve vazo kelimelerinin birlikte ele alınmasını gerektirdiğini vurgulamaktadır. Öğrencinin verdiği yanıtı sonraki söz sırasında tekrar yoluyla onayladıktan sonra cevabı bulmayı sağlayan soruyu ve cevabı yeniden söylemektedir. Öğrencinin cevabının ardından cevabı tekrar edip onaylayan öğretmen hemen peşinden soru sıfatı kullanarak sözcüğün görevini belirtmekte ve sonraki seçeneğe geçmesi için öğrenciye sözel yönlendirmede bulunmaktadır. 16. satırda seçeneğin okunmasının ardından "ha" diyerek öğrencinin devam etmesini sağlayan öğretmen, 19. satırda öğrencinin cevabını tekrar yoluyla onaylamaktadır. Ayrıca öğretmenin dersin pedagojik hedeflerine ulaşmak için sözcüğün birlikte kullanıldığı sözcüğün türünü belirtmekte ve görevini bulmak için gereken soruyu yinelemektedir. 20. satırda sorusunu kendi başlatımlı kendi onarımla yeniden soran öğretmene öğrenci "zaman zarfュ” yanıtını vermektedir. Öğretmen, bu cevabı 22. satırda tekrar ederek onayladıktan sonra sıradaki seçeneğe geçiş için sözel yönerge vermektedir. Öğretmen, sözel yönergesinde sorunun doğru cevabının bulunmasına rağmen diğer seçenekteki sözcüğü inceleme isteğini "yine" sözcügünü kullanarak göstermektedir. Öğrencinin seçeneği okuyup cevabı vermesinin ardından cevabı tekrar yoluyla onayladıktan sonra vurgulu olumlu değerlendirme ile geçiş yapmayı sağlamaktadır. Son seçeneği okuyan ve ardından sözcüğün türünü söyleyen öğrenciye öğretmen, son satırda doğrudan vurgulu olumlu değerlendirme vererek soru ile ilgili öğrenci etkileşimini sonlandırmaktadır.

\section{Sonuç, Tartışma ve Öneriler}

$\mathrm{Bu}$ çalışmada, konuşma çözümlemesi yönteminin tanımış olduğu verinin kendisine dayalı mikro analitik bakış açısı sayesinde Türkiye' de çoğunlukta olan bir kesimin yegâne aracı olan ders kitabının işlendiği sınıf içi etkileşim örneği incelenmiştir. Bu incelemede Türkçe öğretmeninin etkinliklerin tekrarlı yapısı gereği sınıf kültürünü soru-cevap etkileşimi üzerine kurguladığı görülmektedir. Bu etkileşimlerde başlangıç-yanıt-dönüt veya değerlendirme etkileşimleri olarak ortaya çıkabilmekte, bu veri örneğinde de genellikle öğretmen 
baskınlığında gerçekleşmektedir. Ele alınan üç kesitte öğretmenin ders içinde kullanmış olduğu etkileşimsel kaynaklar ile bunların hangi amaçla ve ne sıklıkta kullanıldığg Tablo 1'de listelenmiştir. Her üç kesitte de ders kitabında yer alan etkinliklerin işlendiği görülmekte, farklı günlerde yapılmış olmalarına ve farklı içeriklere sahip olmalarına rağmen ders işleme sürecinin benzer biçimde gerçekleştirildiği görülmektedir.

Dil sınıflarında, sınıf içi etkileşimin verilen görevler dizisi olarak ilerlediği görülmekte, bu görevlerin konuşmanın niceliğini ve niteliğini etkilediği gözlenmektedir (Huth, 2011). Öğretmenin her üç etkinlikte de söz sırası dağıtımını kendisinin gerçekleştirdiği; öğrencilerin yanıtlamaya gönüllü olma durumlarında dahi başlatımlarının belirli bir sınırda kaldığı görülmektedir. Öğrenci katkılarının belirli kalıplar dâhilinde tekrar ettiği (Huth, 2011), etkinliklerin etkileşimi soru-cevap etkileşimi şeklinde sınırlandırdığı açık biçimde izlenebilmektedir. Türkçe ders kitaplarında yer alan etkinlik örneklerinin sınıf içi etkileşim düzeni, öğrencilerin tüm etkinlikleri soru olarak algılamasına dolayısıyla da öğretmenin söz sırası dağıtımı yapmasını beklemesine neden olmaktadır. Bununla birlikte öğretmenin bir sınıf kültürü oluşturduğu, öğrencilerin söz sıralarını oluşturma biçimlerinden de öğrencilerin bu oluşuma hâkim olduğu (örneğin Kesit 1'de vurgulu olumlu değerlendirmenin ardından söz alan öğrenciler vurgulu olumlu değerlendirme unsuru kullanımının geçişe işaret ettiği bilgisi ile hareket etmektedir) düşünülmektedir.

Öğretmen, sınıf içi etkileşimin en tipik etkileşim unsurlarından biri olan (Walsh, 2013) soru-cevap etkinliklerinde üçüncü söz sıralarında öğrencileri değerlendirmekte ve onaylamaktadır. Ayrıca öğretmenin soru-cevap biçiminde ilerleyen bu etkinliklerin dönüt / değerlendirme aşamasında yalnızca sözel yanıtlarla doğrudan değerlendirme yapmakla kalmadığı, "onay verme” işlemini birden çok ve farklı biçimde gerçekleştirdiği görülmektedir. "Konuşmada aktarılan anlamları pekiştirmek, sözlük anlamlarını açık hâle getirmek, uzun söz sıralarında uyumu sürdürmek ve bağlamdan kopmanın önüne geçme” (Belhiah, 2013) gibi biçimlerde kullanılan beden dilinden yararlanan (Whitehead, 2011) öğretmen, değerlendirme dizisini oluştururken bununla sınırlı kalmamakta örneğin "hıh" tepkisi ile söylem belirleyicilerden yararlanmaktadır (Girgin \& Brant, 2019). Öğretmenin, onay ve dönüt vermenin birden fazla, farklı biçiminden yararlanması sınıf içinde etkileşim sürekliliği açısından bir hız kazanılmasını sağlamakta, öğrencilerin yanıtlamaya gönüllü olma durumları da bu kullanımlara aşina olduklarını göstermektedir. Üçüncü söz sırasında oluşturulan bu tip kullanımların aynı zamanda dönütün eksikliğine de işaret ettiği, soruyu yanıtlayan öğrenci dışındaki öğrencilerin anlamadığı durumlarda etkileşime katılmasını da güçleştirdiği 
söylenebilir. Öğretmenin öğrenci katkılarını şekillendirme (Can-Daşkın, 2015) ve genişletme için çabaladığı, öğrenci yanıtlarını düzenlerken sık sık öğretmen-öğrenci ses yansımasından yararlandığg görülmektedir. Öğrencilerin yanıtlarını tekrar ederek onaylamakta, bu yanıtlarla birlikte veya bu yanıtları düzenleyerek doğru formları ve yeğlenen yanıtları sezdirmektedir. Öğretmen, öğretmen-öğrenci ses yansımasını kullanarak örtük onarım gerçekleştirmektedir.

Öğretmen, etkinlik sürecinde vurgulu olumlu değerlendirme unsurlarından da yararlanmakta; bunu hem etkileşim kapatma (case closed, Batlle, 2021; Wong ve Waring, 2009) hem de geçişi ifade etmede (Batlle, 2021; Brophy, 1981) kullanmaktadır. Alanyazında vurgulu olumlu değerlendirmelerin kullanımının olası öğrenme firsatlarının önüne geçebileceği dolayısıyla bu unsurlardan yararlanılırken dikkatli olunması gerektiği ifade edilmektedir (Wong \& Waring, 2009). Öğretmen, bu unsurlardan Kesit 1'de ağırlıklı olarak etkileşim sürdürme işleviyle yararlanmış, sonraki soruya geçildiğine işaret etmiştir. Kesit 3 'te ise vurgulu olumlu değerlendirme unsurunun hemen ardından cevabın gerekçesini tekrar etmiş, söz konusu etkinliğin kapandığına ve daha fazla katkı istenmediğine işaret etmiştir. Bu bakımdan bakıldığında öğretmenin vurgulu olumlu değerlendirme unsurlarından yararlanmayı ders işleme süreci içinde farklılaştırdığı görülmektedir. Ayrıca öğretmenin Türkçe dersinin niteliği gereği üstdilsel gönderime de başvurduğu, dil bilgisi açısından fark ettirmeyi amaçladığı kuralları, örnekleri etkinlikler ve tekrarlar aracılığgyla öğrencilere vermeye çalıştığı görülmektedir.

Dil eğitiminin gerçekleşme sürecinde öğretim programları sürecin tüm parçalarını etkilemektedir. Ders materyalleri hazırlanırken kitap yazarları programdaki çerçeveyi takip etmekte, kitaplardaki yaklaşım öğretmenin ders içindeki uygulamalarını biçimlendirmektedir. Ancak ders kitaplarının içeriği ve düzeni, etkileşimli ders işlemeye her zaman imkân tanımamaktadır. Ders içinde kullanılacak materyallerin etkileşimsel açıdan verimli olarak kullanılabilecek materyaller olması (Seedhouse, 2005); öğretmenler için izlence niteliği taşıması, öğrenme hedeflerine ve yöntemlerine uygun olması, eğitimi tüm öğrenciler için standart hâle getirirken çeşitli ve etkili öğretim olanakları sunması (Richards, 2001) gerekmektedir. Kullanılan ders kitapları konuşmanın sınırlı özelliklerine sahip modeller içermekte, gerçek konuşma pratiklerine imkân sunmamaktadır (Pitaksuksan \& Sinwongsuwat, 2020). Kullanılan materyallerin, bu örnekte ders kitabının niteliği öğretmenin ders işleme süreçlerini etkilemekte, etkinliklerin soru-cevap sınırında kalmasına neden olmakta, etkileşimli öğrenme hedefine erişilmesine mani olmaktadır. Etkinliklerin bu özelliği, öğrencilerin derse katılımlarını etkilemektedir. Etkinliklerde sözel iletişimde kullanılabilecek 
sorular ağırlıklı olduğundan soru-cevap etkileşimi yalnızca yanıtlayan öğrenci ve öğretmenle sınırlı kalmakta, diğer öğrenciler etkinliğin takipçisi olup etkileşimin bir parçası hâline gelememektedir.

Örneğin Kesit 1'deki etkileşim sürecini oluşturan etkinlik, ders kitabında aşağıdaki biçimde yer almaktadır (Şekil1). Etkinlik örneğine bakıldığında bu etkinliğin bir öğretim süreci oluşturmaktan çok bir ölçme-değerlendirme niteliği taşıdığı görülmektedir. Etkinliğin niteliği gereği öğretmen, ders kitabını takip ederek, etkileşimi soru-cevap bağlamında kurgulamak ve öğrencileri sorulara verdikleri yanıtlar üzerinden değerlendirmektedir. Öğretmenin kitaplarda yer alan etkinlikleri çeşitlendirerek öğretmen-öğrenci ve öğrenciöğrenci etkileşimlerini arttıracak biçimde uygulamadığı görülmüştür.

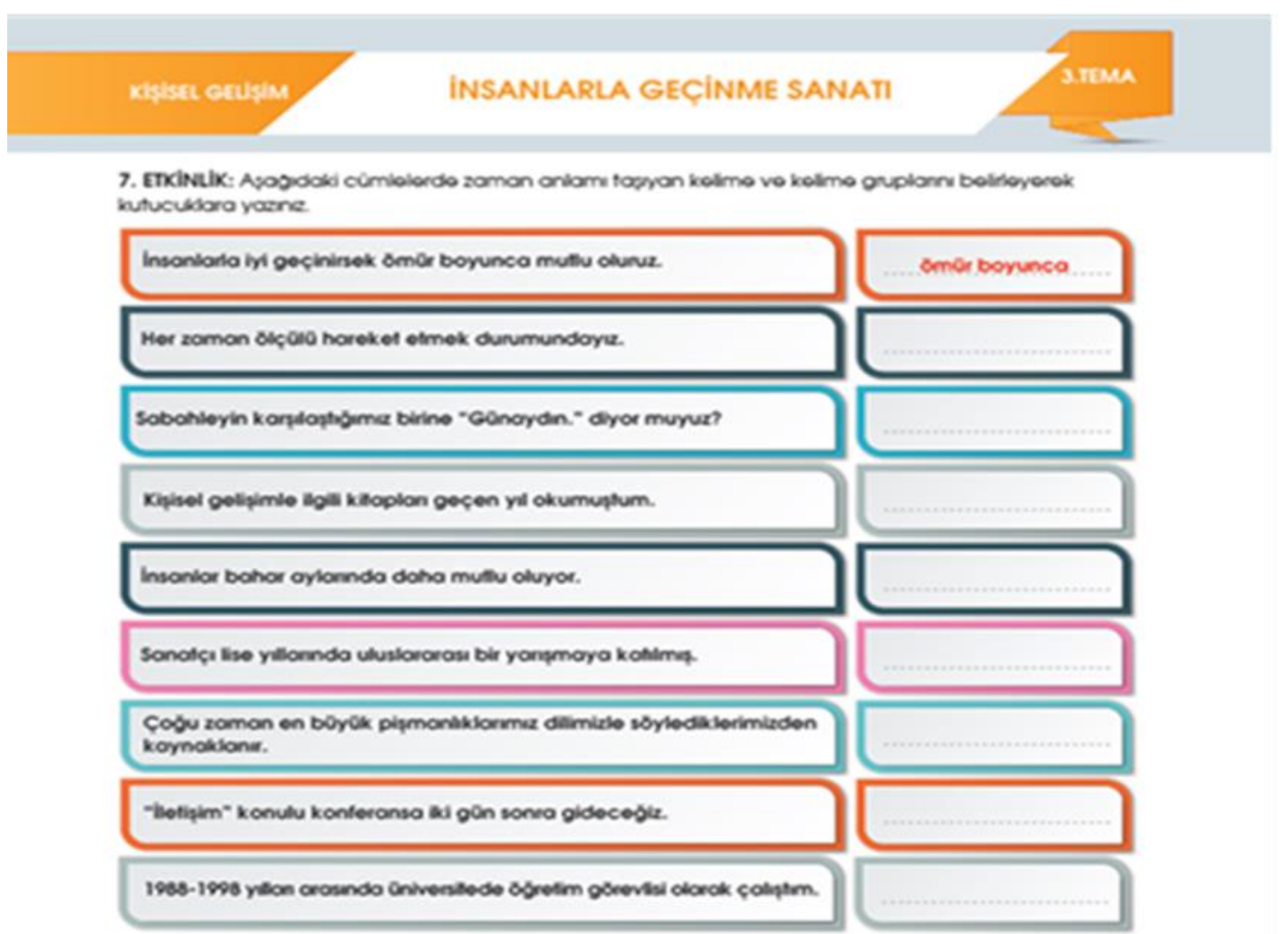

\section{Şekil 1. Kesit 1'deki etkileşim sürecini oluşturan etkinlik}

Ders işleme süreçlerinde gerçekleşen etkileşimin ayrıntılı biçimde incelenmesinden öğretmenlerin kendi uygulamalarının sonuçlarını görmesinde ve öz düzenleme yapmasında yararlanılabilir. Konuşma çözümlemesi yöntemi ile incelenen veri, yalnızca Türkçe dersi öğretim uygulamaları değil, öğretmen yetiştirme alanına yönelik de çıkarım yapmaya olanak sağlayacaktır. Sert ve Seedhouse (2011), konuşma çözümlemesi yöntemini anlattıkları 
çalışmalarında sınıf içi etkileşimin etkisini gören öğretmen adaylarının etkileşimsel alan, öğrenci katkısını şekillendirme, etkili dönüt verme, öğretmen konuşmalarının doğru kullanımı, etkileşimsel farkındalık bakımından öğretmen yetilerini etkileyeceği çıkarımında bulunmuştur.

Ders kitaplarının temel ve en ulaşılabilir ders materyali olduğu düşünüldüğünde ders kitaplarının niteliğine pratikte gerçekleşen öğretim uygulamaları ile bakmak bu ve bunun gibi mikro analitik çalışmalarla mümkündür. Milyonlarca öğrenciye ulaşan kaynakların niteliklerinde gerçekleşecek en ufak bir olumlu değişim eğitimde olumlu etkilere neden olacak, Türkçe dersi öğretim programları ile hedeflenen öğrencinin kendi öğreniminden sorumlu olduğu aktif bir öğrenme sürecini destekleyen kaynakların hazırlanmasında bir adım olabilecektir.

Konuşma çözümlemesi bakış açısında kilit yön, araştırmacının gözlemlediği tüm derslerde meydana gelen etkileşimsel dizi ve sosyal eylemleri seçebilmektir (Kääntä, 2021). $\mathrm{Bu}$ veride öğretmen eylemleri, öğretmen-öğrenci etkileşimleri tanımlanabilir bir sosyal eylem özelliği göstermektedir. Ayrıca veriden, konuşma çözümlemesinin yaklaşımı aracılığıyla öğretmenin sınıf içindeki uygulamalarının etkileşimsel görünümlerine dair bilgilendirme/farkındalık kazandırmada yararlanılabilir.

Etik Kurul İzin Bilgisi: Bu araştırma, Hacettepe Üniversitesi Etik Komisyonu'nun 23 /10/2018 tarihli 35853172-044. sayılı kararı ile alınan izinle yürütülmüş̧ür.

\section{Yazar Çıkar Çatışması Bilgisi}

Yazarlar çıkar çatışması olmadı̆̆ını beyan etmektedir.

\section{Yazar Katkısı}

Yazarlar çalışmaya eşit oranda katkı sağlamıştır. 


\section{Kaynakça}

Akgül, A., Demirer, N., Gürcan, E., Karadaş, D., Karahan, İ. \& Uysal, A. (2019). Ortaokul ve imam hatip ortaokulu 7. sınıf Türkçe ders kitabı. Milli Eğitim Bakanlığı Yayınları.

Avcı, M. (2020). Vurgulu olumlu değerlendirmenin Türkçe dersleri sınıf içi etkileşiminde kullanımının incelenmesi. [Yayımlanmamış yüksek lisans tezi, Hacettepe Üniversitesi Eğitim Bilimleri Enstitüsü]. Hacettepe Üniversitesi.

Badem-Korkmaz, F., \& Balaman, U. (2020). Third position repair for resolving troubles in understanding teacher instructions. Linguistics and Education, 60, 1-13. https://doi.org/10.1016/j.linged.2020.100859

Batlle, J. (2021). "Muy bien" as a transition token in teacher-student interactions in the Spanish as a foreign language classroom. System, 97(2), 1-12 https://doi.org/10.1016/j.system.2020.102438

Belhiah, H. (2013). Using the hand to choreograph instruction: On the functional role of gesture in definition talk. The Modern Language Journal, 97(2), 417-434. https://doi.org/10.1111/j.1540-4781.2013.12012.x

Brophy, J. (1981). Teacher praise: A functional analysis. Review of Educational Research, 51(1), 5-32. https://doi.org/10.2307/1170249

Burden, P. (2013). Classroom management: creating a successful k-12 learning community. Wiley.

Can-Daşkın, N. (2015) Shaping learner contributions in an EFL classroom: Implications for L2 classroom interactional competence, Classroom Discourse, 6(1), 33-56. https://doi.org/10.1080/19463014.2014.911699

Can-Daşkın, N. (2017). A conversation analytic study of reference to a past learning event in L2 classroom interaction: implications for informal formative assessment [Doctoral dissertation thesis, ODTÜ SBE]. ODTÜ.

Can-Daşkın, N., \& Hatipoğlu, Ç. (2019). Reference to a past learning event in teacher turns in an L2 instructional setting, Journal of Pragmatics, 142, 16-30. https://doi.org/10.1016/j.pragma.2018.12.023

Coulon, A. (2015). Etnometodoloji. Küre Yayınları.

Çakır, H. (2017). Türkçe derslerinde söylem belirleyicisi olarak ‘yani’nin işlevleri. H. Ülper (Ed.), Türkçe Eğitimi Güncel Araştırmaları içinde. Pegem Akademi Yayınları.

Çakır-Sarı, H. (2020). Türkçe öğretmenlerinin söylem belirleyicisi kullanımı. Dil Dergisi, 171(1), 75-90. 
Çimenli, B., \& Sert, O. (2017), Orientations to linguistic form in meaning and fluency contexts in a Turkish as a foreign language classroom. In G. Schwab, S. Hoffmann, \& A. Schön (Eds.), Interaktion im fremdsprachenunterricht: beiträge aus der empirischen forschung. Berlin.

Fagan, D. S. (2014). Beyond "excellent!": uncovering the systematicity behind positive feedback turn construction in ESL classrooms. Novitas-ROYAL(Research on Youth and Language), 8(1), 45-63.

Girgin, U., \& Brandt, A. (2019). Creating space for learning throuhg 'Mm hm' in a L2 classroom: Implications for L2 classroom interactional competence, Classroom Discourse, 11(1), 61-79. https://doi.org/10.1080/19463014.2019.1603115

Goffman, E. (2017). Etkileşim ritüelleri: Yüz yüze davranış üzerine denemeler. Heretik Yayınları.

Göğüş, B. (1983). Anadili eğitim programlarının niteliği. Türk Dili Dergisi Dil Öğretimi Özel Saylsl, 379, 40-48.

Hellerman, J. (2003). The interactive work of prosody in the IRF exchange: Teacher repetition in feedback. Language in Society, 32(1), 79-104.

Heritage, J., \& Clayman, S. (2010). Conversation analysis: Some theoretical background. Talk in Interaction, Blackwell Publishing.

Huth, T. (2011). Conversation analysis and language classroom discourse. Language and Linguistics Compass 5(5), 297-309.

Kääntä, L. (2021). Multimodal perspective into teachers' definitional practices: Comparing subject-specific language in physics and history lessons.S. Kunitz, N. Markee \& O. Sert (Eds.), Classroom-based conversation analytic research: Theoretical and applied perspectives on pedagogy içinde. Springer Publishing.. https://doi.org/10.1007/978-3030-52193-6_11

Karatay, H., Dolunay, S.K., \& Savaş, Ö. (2014). Türkçe öğretmenlerinin etkin dinleme ve dönüt durumları. Ana Dili Ĕgitimi Dergisi, 2(4), 85-106.

Kardaş-İşler, N. (2019). İlkokul sosyal bilgiler dersinde öğrenci başlatımları ve ögrrenme firsatları: Bir konuşma çözümlemesi çalışması. [Yayımlanmamış doktora tezi, Hacettepe Üniversitesi Eğitim Bilimleri Enstitüsü]. Hacettepe Üniversitesi.

Kimura, D.; Malabarba, T., \& Hall, J. K. (2018). Data collection considerations for classroom interaction research: A conversation analytic perspective. Classroom Discourse, 9(3), 185-204. 
Kirsch, C., \& Seele, C. (2020). Translanguaging in early childhood education in Luxembourg: From practice to pedagogy. Inclusion, Education and Translanguaging içinde (ss.6381). Springer Publishing.

Lee Y. A. (2021). Tacing teachers' ordering decisions in classroom interaction. S. Kunitz, N. Markee, \& O. Sert (Eds.), Classroom-based conversation analytic eesearch: Theoretical and applied perspectives on pedagogy içinde. Springer Publishing.. https://doi.org/10.1007/978-3-030-52193-6_11

Leslie, C. (2017). Group cohesion and learning opportunities in peer interaction. Porta Linguarum Monograph, 2, 245-265.

MEB (2006). İlköğretim Türkçe dersi (6, 7, 8. sınıflar) öğretim programı. MEB TTKB.

MEB (2019). Türkçe dersi ögretim programı (1, 2, 3, 4, 5, 6, 7 ve 8. sinıflar). MEB TTKB.

Mehan, H. (1979). Learning lessons: Social organisation in the classroom. Harvard University Press.

Onan, B. (2011). Anlama sürecinde Türkçenin yapısal işlevleri. Nobel Akademik Yayıncılık. Özbay, M. (2006). Türkçe özel ögrretim yöntemleri I. Ankara: Öncü Kitap.

Özcan, G., \& Aksan, Y (2017). Sözlü Türkçede evet'in görünümleri: Sözlü Türkçe derlemi'nden bulgular. Mersin Üniversitesi Dil ve Edebiyat Dergisi, 14(2), 15-35.

Pitaksuksan, N., \& Sinwongsuwat, K. (2020). CA-informed interactional feature analysis of conversations in textbooks used for teaching English speaking in Thai secondary schools. English Language Teaching, 13(7), 140151.https://doi.org/10.5539/elt.v13n7p140

Richards, J. C. (2001). The role of textbooks in a language program. Cambridge University Press.

Rowe, M. B. (1972). Wait-time and rewards as instructional variables, their influence on language, logic, and fate control: Part one - wait-time. Journal of Research in Science Teaching 11(2), 81-94.

Scales, P. (2015). Yaşam boyu öğrenme ve öğretim. Palme Yayıncılık.

Seedhouse, P. (2005). Conversation analysis and language learning. Language Teaching, 38, 165-187.

Sert, O., Balaman, U., Can-Daşkın, N., Büyükgüzel, S., \& Ergül, H. (2015). Konuşma çözümlemesi yöntemi. Dil ve Edebiyat Dergisi, 12(2), 1-43.

Sert, O. (2015). Social interaction and L2 classroom discourse. Edinburgh University Press. 
Sert, O., \& Seedhouse, P. (2011). Introduction: conversation analysis in applied linguistics. Special Issue: Conversation Analysis in Educational and Applied Linguistics, NovitasROYAL (Research on Youth and Language), 5(1), 1-14.

Shi, J. (2015). Okay as an embodied backchannel in classroom interaction. ELT Voices, 5(5), 1-12.

Sumruk, H. (2019). Yabancı dil olarak Türkçe öğretiminde etkileşim ve konuşma çözümlemesi yöntemiyle kelime öğretimi: A2 düzeyi, [Yayımlanmamış Yüksek Lisans Tezi, Türkiyat Araştırmaları Enstitüsü]. Hacettepe Üniversitesi.

Tainio, L., \& Slotte, A. (2017). Interactional organisation and pedagogic aims of reading aloud practices in L1 education. Nordic Journal of Literacy Research, 3, 61-82. https://doi.org/10.23865/njlr.v3.469

TÜBA Online Bilim Terimleri Sözlügü, 03.05.2021, http://www.tubaterim.gov.tr/

Walsh, S. (2013). Classroom discourse and teacher development. Edinburgh University Press.

Waring, H. Z. (2008). Using explicit positive assessment in the language classroom: IRF, feedback, and learning opportunities. The Modern Language Journal, 92(4), 577-594. https://doi.org/10.1111/j.1540-4781.2008.00788.X

Whitehead, K. A. (2011). Some uses of head nods in "third position" in talk-in-interaction. Gesture, 11(2),103-122. https://doi.org/10.1075/gest.11.2.01whi

Wong, J., \& Waring, H.Z. (2009). 'Very good' as teacher response. ELT Journal, 63(3). 195203. 


\title{
Using Interactional Resources in Turkish Lessons* \\ Merve AVCI**, Özay KARADAĞ ${ }^{* * *}$
}

- Received: 26.06.2021 • Accepted: 19.11.2021 • Online First: 19.11.2021

\begin{abstract}
This study aims to determine the interactional resources that the teacher uses in classroom interaction and the functions of these resources. Data were collected from a classroom where Turkish was taught as a mother tongue. The conversation analysis method was used in the study. In the class, three cameras (behind the teacher's desk to see the students and at the entrance of the door, behind the student rows to see the teacher) and two audio recorders (points away from the cameras) were used. Twenty-seven lessons were recorded. Interactional resources such as using waiting time, teacher-student voice reflection, using body language, saying the student's name in order of speech, referring to past learning events, metalinguistic reference/preference, using discourse markers, shaping student contribution, expansion, stress-intonation, explicit positive assessment, were used by the teacher. These uses of the teacher are exemplified in three sections obtained from the data.
\end{abstract}

Keywords: Turkish, interactional resources, conversation analysis, classroom interaction

\section{Cited:}

Avci, M., \& Karadağ, Ö. (2022). Using interactional resources in Turkish lessons. Pamukkale University Journal of Education, 55, 1-26.doi: 10.9779.pauefd. 956084

\footnotetext{
* This article was produced from the master's thesis titled "An Investigation Into Explicit Positive Assessment Use In Turkish Language Classroom Discourse" prepared by the first author under the supervision of the second author.

** Res.Assist, Hacettepe University, 0000-0002-4007-558X, merve avci@hacettepe.edu.tr

*** Prof. Dr., Hacettepe University, 0000-0003-4596-1203, ozaykaradag@,hacettepe.edu.tr
} 


\section{Introduction}

The interaction, defined as "A communication process based on mutual sharing between two or more individuals." in the TÜBA Academy of Sciences Turkish Science Terms Dictionary, emerges subject to certain rules in social areas. People perform their relations with each other, interact and acquire various identities, learn, teach, and constantly negotiate according to these rules in interaction processes (Sert, 2015). Through the interactions established in social life, socialization is ensured, and various institutions are created; courtrooms, parliaments, schools, and even classrooms are maintained through interaction (Sert, 2015).

Social interactions are shaped in the context of individuals' roles as part of society by situations and times. Roles such as parent-child, patient-doctor, landlord-tenant, and teacherstudent can be given as examples for those shaped in various situations, times, and places. In the landlord-tenant interaction, the landlord's obligations are doing the necessary things to maintain the house; the tenants are to pay the rent and not damage the house. In the same example, where the tenant is a doctor by profession and the landlord is a patient of him, the roles will vary. Goffman (2017) explains this situation as the rules of behavior in social life are realized in the focus of obligations and expectations. Accordingly, societal obligations require the individual to observe certain moral boundaries; expectations are the expected behavior patterns shaped by the individual's role (Goffman, 2017). The roles of teachers and students defined in the interactions that occur in the classroom interaction pattern can be shown as examples of certain obligations and expectations: While the teacher is expected to provide information or allow it to be discovered, it can be said that the student must obtain the information in question.

The interaction, which appears in the classroom as student-teacher, teacher-student, student-student, and student-material interaction, is shaped in the context of social roles. Teacher and student roles are also formative in the planning and implementation of teaching processes. In terms of learning-teaching approaches, while the teacher mostly carries out a process in which the teacher is dominant, and interaction is expected in the classrooms that can be considered traditional, in the classrooms that can be considered modern, the expectation is that the student takes an active role in his learning.

Curriculums are effective in the whole learning-teaching process. Teaching approaches, materials, educational environment designs, implementation phase, etc., all elements are determined within the framework drawn by the curricula. The interaction in the classroom also shapes the approach on which the programs are based. With the curriculum 
M. Avcı \& Ö. Karadağ / Pamukkale University Journal of Education, 55, 1-26, 2022

changes made in Turkey in 2005-2006, a learning-teaching approach was adopted that would increase classroom interaction (MEB, 2006). Determining the learning objectives as an outcome determines the student's role as an active participant in the classroom. In the development of basic language skills, it is envisaged to use activities and activities in which the student can exhibit these characteristics. According to the role of the teacher required by the learning-teaching approaches in the classroom, the teacher's job is to help students relate to and make sense of new information with existing ones (Scales, 2015, p. 39). In the learning process, the teacher is expected to help the student learn and design a learning environment that will allow students to interact with each other and learn from peers. It is aimed that students get into an interactive process through activities and take an active role in the classroom. For this reason, the activities used in the course teaching process should be such that the students take a more active role in the classroom. It is possible to see these roles and their effects, which are very decisive on teaching practices, by examining in-class interaction.

Although the classroom is the environment in which language teaching occurs informal education, the knowledge about the processes taking place in the classroom is limited (van Lier, 1988). The arrangement of learning environments has an impact on the realization of learning. Van Lier (1988), "teaching" alone cannot ensure the realization of learning; he stated that it could reveal conditions that enable or hinder learning (p. 32). However, in his justification for the studies carried out in the classroom, he stated that the knowledge about what is going on in the classroom is limited and that it is necessary and valuable to increase this knowledge, and that this is possible with the data obtained from the classroom (van Lier, 1988, p. 37). He also stated that the data obtained from the classroom can be interpreted from the context of the classroom and that this context is essential not only in linguistic and cognitive terms but also in terms of social context (van Lier, 1988, p. 37). Mehan (1979) also stated that understanding the classroom order can be seen with a holistic approach covering the whole "classroom." Examining the effect of social and pedagogical processes in language classes on learning is possible by examining the context of interaction (Sert, 2015). Teachers and students communicate pedagogical goals through face-to-face classroom dialogue, and it is this interaction that puts learning into action (Huth, 2011). In the classroom environment, participants create a common meaning through interactions, and the functionality of this common meaning and classroom dialogue can be determined by examining the classroom discourse (Mercer, 2008).

The number of studies focusing on classroom interaction in Turkish lessons is extremely limited. Some of these studies focused on classroom discourse (Çakır, 2017; Çakır- 
Sarı, 2020; Özcan \& Aksan, 2017), some focused on a certain part of class interaction (e.g. feedback) (Karatay, Dolunay, \& Savaş, 2014), and the other studies were the study was conducted on the examination of certain contexts in teaching as a foreign language (Çimenli $\&$ Sert, 2017; Sumruk, 2019). On the other hand, when the studies conducted abroad are examined, it is seen that many studies examine classroom interaction from a microanalytical perspective. There are studies conducted in both mother tongue teaching contexts and foreign language/second language teaching contexts. Among these, some studies focus on the "repairs" made by the teachers during the conversation that students do not express verbally but have difficulty in understanding (Badem-Korkmaz \& Balaman, 2020), exemplifying the use of the third turn in second language teaching in a way that can provide learning opportunities (Girgin \& Brandt, 2019), past learning in the context of foreign language teaching, which exemplifies benefiting from the events in classroom interaction (Can-Daşkın, 2017; Can-Daşkın \& Hatipoğlu, 2019), aiming to reach pedagogical goals by shaping the teacher's student responses (Can-Daşkın, 2015), emphasizing on the use of positive evaluation (Batlle, 2021; Fagan, 2014; Waring, 2008; Wong \& Waring, 2009), examining the effect of reading aloud on classroom interaction patterns (Tainio \& Slotte, 2017), examining the use of stress and intonation in classroom interaction (Hellerman, 2003), dealing with participation in this process (Kirsh \& Scale, 2020).

In examining classroom interaction, observing how the teacher uses interactive resources to make the conceptual area of the lesson accessible to students can be done through a natural data-based method such as the conversation analysis method (Kääntä, 2021). In classroom interaction, the teacher usually initiates, develops, and closes the subject, so the teacher's assumptions, goals, and concerns about teaching, as the person who manages the interaction, shape the interaction (Lee, 2021). Language teachers should also pay attention to the social dimension of language teaching while planning their teaching practices (Leslie, 2017). Observing and examining teaching practices provides insight into language teaching in both mother tongue teaching contexts and second language/foreign language teaching contexts (Kääntä, 2021). Learning and teaching are done with verbal elements, and nonlinguistic/nonverbal elements are used to create meaning and context. Examining all these is necessary to understand how language is learned, especially in language classes (Kääntä, 2021).

A holistic view of the classroom environment in Turkish lessons is important in terms of providing information about the "what is" and "what is useful" of teaching practices. This 
M. Avc1 \& Ö. Karadağ / Pamukkale University Journal of Education, 55, 1-26, 2022

study aims to reveal how the teacher uses interactive resources in the classroom interaction in Turkish lessons by using the microanalytic perspective of the conversation analysis method.

\section{Method}

The conversation analysis method was used in the study. It carries an ethnomethodological perspective based on conversation analysis. Ethnomethodology evaluates members' actions in social life within their processes (Coulon, 2015). Conversation analysis also starts from the data itself in the analysis of the data. Conversation analysis, which examines the order of conversations in interaction and the social actions that occur in this order, is a set of methods and approaches that can objectively reveal how people understand each other in the natural interaction process (Sert et al., 2015). Sert et al. (2015) listed the principles of the method as follows: the interaction is organized systematically, the contributions in the interaction shape the context and are shaped by the context, the analysis is done from the data, the analysis is performed with an insider perspective (p. 6). Mart1 (2015) also describes the principles of conversation analysis, "The conversation is regular; contribution to the conversation is in a consecutive, and currently formed structure. Speakers both contribute to the interaction and can be understood thanks to this sequential structure; the analysis of the conversation is based on the conversation itself "(p. 269). Based on the principles listed, it can be said that the method of conversation analysis examines the talk-in-interaction order from the data itself and within the order. Sert and Seedhouse (2011) stated that all details were considered in the analysis and emphasized that speaking in order and talk-in-interaction is the basis of conversation analysis.

In conversation analysis, interaction is examined with the details that emerge in the orientation of the speakers to each other; It is evaluated through interactional resources such as taking turns to speak, repair, and preference (Sert et al., 2015). Conversation analysis is examined based on the conversation itself; for example, the order of taking and forming a verbal order is analyzed by looking at the order of conversation formed by the speaker after the order of conversation before him and the order of conversation that comes after him, which is considered as an indicator of understanding and comprehension (Heritage \& Clayman, 2010 ). Taking turns to speak order can progress by the current speaker choosing the next speaker with a sequential double use, gaze, or address, or by the next speaker taking the turn of his own (Sacks, Schegeloff, \& Jefferson, 1974; cited in Sert et al., 2015). Along with the turntaking design, the sequence order, repair, and preference patterns are among the interactive elements in which the conversation is followed in the interaction. Conversation analysis 
focuses on the sequential and simultaneous occurrence of the interaction rather than making determinations with idealized thoughts about the classroom order (Kimura et al., 2018, p. 185). Conversation analysis enables the observation and examination of the non-verbal aspects of conversation that occur in natural interaction, based on intersubjective (the themes put forward by the participants in understanding and understanding each other).

\section{Data Collection Process}

First of all, permission was obtained from Hacettepe University Senate Ethics Committee on 23.10.2018 for the research. After the permission of the ethics commission, the necessary permissions were obtained from the Ankara Provincial Directorate of National Education. Upon the completion of these permissions, the school administration where the study data will be collected was contacted, and after the approval of the administration, a voluntary participation form was obtained from the teachers, parents, and students. With the completion of the permissions, the data collection phase started. During the data collection process, 3 hours of recording could not be made due to the announcement of a 1-day snow holiday throughout Ankara and the written exam application, and the remaining recordings were completed as planned. In six weeks, the first week four lessons (117 minutes), the second week three lessons (103 minutes), the third week five lessons (169 minutes), the fourth week five lessons (171 minutes), fifth week five lessons (179 minutes) and sixth week five lessons (181 minutes), in all 27 lessons/920 minutes. The 10-hours recording selected from the obtained data constitutes the study data.

\section{Research Group and Classroom}

Data were collected from a public school in the central Etimesgut district of Ankara. In the class, three cameras (behind the teacher's desk to see the students and at the entrance of the door, behind the student rows to see the teacher) and two audio recorders (points away from the cameras) were installed. In this class, where Turkish is taught as a mother tongue, Turkish lesson is taught for five hours per week (7th-grade level). The Turkish course book is used as the main material.

\section{Data Analysis}

Before proceeding to the analysis phase, the recordings were watched without any focal point, and orthographic transcripts of all recordings were prepared. As the focal point, the interactional resources used by the teacher were determined. It has been observed that relevant, interactive resources frequently emerge in teacher-student interactions, and selected sections with this feature. In the study, two sections were taken as examples, and the place 
and forms of interactional resources in the classroom interaction processes were tried to be explained together with the interaction order

\section{Findings}

Within the scope of the research data, 48 sections were identified as teacher-student interaction samples within ten lesson hours. Three sections representing the use of interactional resources were taken from the mentioned sections, and it was determined that ten different interactional resources were used forty-five times in these sections (Table 1). It has been observed that the teacher distributes the order of conversation herself in the mentioned interaction examples, gives the students a waiting time to create and organize their answers, and uses emphatic positive evaluation elements and discourse determinants to control and maintain the course of the interaction. On the other hand, it has been seen that she benefited from metalinguistic references in the examples that include grammar topics. There are examples where she deliberately used and emphasized grammatical structures.

Table 1. Interactional resources, their functions and frequency

\begin{tabular}{|c|c|c|c|}
\hline Extract & Interactional Resources & Intended Use & Frequency \\
\hline \multirow[t]{6}{*}{ Extract1 } & Explicit Positive Assessment & $\begin{array}{l}\text { - Maintain activity } \\
\text { - Close activity or switch } \\
\text { activity }\end{array}$ & $\begin{array}{l}5 \\
1\end{array}$ \\
\hline & Teacher-student echo & - Confirmation & 4 \\
\hline & Nonverbal communication & $\begin{array}{l}\text { - Maintain classroom } \\
\text { order } \\
\text { - Confirm/Assess }\end{array}$ & $\begin{array}{l}1 \\
4\end{array}$ \\
\hline & Saying students' names & - Turn distribution & 5 \\
\hline & Waiting Time & $\begin{array}{l}\text { Give the student time } \\
\text { to create or edit their } \\
\text { answer }\end{array}$ & 2 \\
\hline & Discourse markers & $\begin{array}{l}\text { - Use discourse markers } \\
\text { - } \quad \text { co mean "go on". } \\
\text { - Draw attention }\end{array}$ & $\begin{array}{l}2 \\
1 \\
1\end{array}$ \\
\hline \multirow[t]{2}{*}{ Extract2 } & Prosody/intonation & - Draw attention & 1 \\
\hline & Discourse markers & - Confirm/Assess & 2 \\
\hline
\end{tabular}




\begin{tabular}{|c|c|c|c|}
\hline & Expansion & $\begin{array}{ll}\text { - } & \text { Fulfillment/elaboration } \\
\text { - Shaping learner } \\
\text { contribution }\end{array}$ & $\begin{array}{l}1 \\
1\end{array}$ \\
\hline & Saying students' names & - $\quad$ Turn distribution & 2 \\
\hline & Waiting time & $\begin{array}{l}\text { - Give the student time } \\
\text { to create or edit their } \\
\text { answer }\end{array}$ & 1 \\
\hline & Explicit Positive Assessment & - Maintain activity & 1 \\
\hline & Epistemic status check & - Information request & 1 \\
\hline Extract 3 & Discourse markers & $\begin{array}{l}\text { - Use discourse makers } \\
\text { to mean "go on". }\end{array}$ & 2 \\
\hline & Nonverbal communication & - Confirm/Assess & 1 \\
\hline & Expansion & - Information request & 1 \\
\hline & Teacher-student echo & $\begin{array}{ll}\text { - } & \text { Confirm } \\
\text { - } & \text { Transition }\end{array}$ & $\begin{array}{l}2 \\
1\end{array}$ \\
\hline & Explicit Positive Assessment & $\begin{array}{l}\text { - Close activity or switch } \\
\text { activity }\end{array}$ & 1 \\
\hline & Metalinguistic reference & $\begin{array}{l}\text { The utilization } \\
\text { presented to the student } \\
\text { through the deliberate } \\
\text { use or asking of a } \\
\text { grammatical structure }\end{array}$ & 1 \\
\hline
\end{tabular}

In Extract1, an example of an interaction pattern in which one of the activities was done between the 18th and 20th minutes of the first lesson of the 2nd semester is given. Beforehand, the instruction that "find the words and phrases which carry the meaning of time" was read, and the teacher asked what is meant by the word meaning time. After the teacher answered her question as "adverb of time", she started the activity. The first line of Extract1 begins with the teacher repeating this answer. 


\section{Extract 1}

(00.18.14.5-00.20.16.9, Süre: 02.02.6)

$\begin{array}{ll}01 \mathrm{~T}: \quad \underline{\text { zaman }} \text { zarfinı bulmamızı istiyo } \\ & \text { want us to find adverb of time }\end{array}$

$02 \quad(1.1)$

03 S1: $\quad$ ya kendi söylüyo ...((anlaş1lmayan konuşma) $)$

the book says itself

$04 \quad \mathrm{~T}: \quad$ alla:h alla:h ya: $\uparrow$

oh really $\uparrow$

05 T: $\quad$ bakiyim $\downarrow$ Ö3 yapmıştır ondan kopya çekelim +Ö3’ün kitabını alıp öğretmen masasına koyup bu kitaptan takip ediyor.

\section{let me see $\downarrow \quad S 3$ made it, let's cheat on it}

+teacher takes S3's book and use her book during that lesson

06

$(0.7)$

07 T:

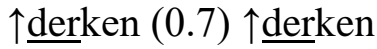

$\uparrow$ theeen

08

aa: $\uparrow$ Ö3 ödevini yapmamış

$a a: \uparrow S 3$, did not do her homework

09 S1: $\quad>$ ha:yır $\uparrow$ ödev değildi ki<

$>$ no: $\uparrow$ this was not a homework<

10 T: $\quad$ tamam (.) tamam

okey (.) okey

11

(1.0) +öğretmen eliyle masaya vuruyor

+teacher slams her hand on the table

$12 \mathrm{~T}$ : >ona bakmiyorum zaten<

$>$ I'm not looking at that<

13

$(0.5)$

14

şşt

shhh

15

$(0.4)$

\footnotetext{
${ }^{1}$ This extract taken from the master thesis of first writer.
} 
It is seen that the teacher took the book of a student from the front row after repeating the information questioned in the instruction saying, "S3 made it let's cheat on it". After expressing surprise that S3 did not do the activity, S1 says that the activity is not homework. Because of the noise in the classroom, the teacher said, "okay, okay," in line 10, gave students a waiting time of 1.0 seconds (Rowe, 1984) in line 11, and slammed her hand on the table in line 12. She tried to restore order in the classroom by saying ">I'm not looking at that $<$ " in the line, saying "shhh" in the 14th line (Girgin \& Brandt, 2011), and with short waits in the 13th and 15th lines (Burden, 2013).
$16 \mathrm{~T}$ :
peki Ö2 $\uparrow(0.5)$
okey, $S 2 \uparrow(0.5)$
17
şu yedinci etkinliği oku bakalım
read the seventh activity
19 S2:
aşağıdaki cümlelerde yer alan

\section{in the sentences below}
20 T: $\quad$ [şşst $]($.)
shh
21 S2: [kelime] ve kelime
[Word) and Word
gruplarını belirleyerek cümleler yazınız (0.3)
write sentences by identifying groups
23
pardon boşluklara yazınız
sorry write in the blanks

The teacher makes the turn distribution herself. After giving a turn to S2 via increasing intonation, she asks the student to read instructions. After a waiting time of 1.3 seconds, while $\mathrm{S} 2$ reads the instruction, the teacher tries to restore the order in the classroom by saying "shh". In line 23 , it is seen that the student has completed reading the instruction by self-initiated self-repair.

24 T: [peki:]

okey

25 S2: [insan]larla iyi geçinirsek ömür boyunca mutlu

if we get along with people

oluruz (0.5) 11 ömür boyunca diyo 
we'll be happy for life

27 T: ömür boyunca (.) zaten örneği yapmış

for life (.) the example has already done

28

evet (.) devam edelim

yes (.) continue

29 S2: $\quad$ her zaman ölçülü hareket etmek durumundayız

we always have to act in moderation

30

(.) 11: (0.9) her zaman

err: (0.9) always

$31 \mathrm{~T}$ : $\quad \underline{\text { ne zaman }} \uparrow$ ölçülü hareket [etmek durumundayız

+başıyla onaylayarak

$\underline{\text { when }} \uparrow$ we have to act in moderation

+nodded her head

32 S2:

[her zaman

[always

$33 \mathrm{~T}$

her zaman (.) zaman zarfi (.)güzel $\uparrow$

always (.) adverb of time (.) $\operatorname{good} \uparrow$

34

$(0.5)$

$\mathrm{S} 2$ reads the example sentence after the teacher confirms the student to continue with the discourse marker. After a waiting time of 0.5 seconds, she repeats the example by saying, "err...life long". It is seen that the teacher continues to interact with the discourse marker after she repeats the phrase and says, "the example has already been done". In line 29, S2 reads the next sentence. After a short waiting time and the sound made to save time (err: in line 30), S3 says "always". In line 31, the teacher pronounces the question of finding the adverb in a rising intonation and aloud, then repeats the sentence. It is seen that S2 also answered before the teacher's repetition was over, and the teacher nodded her head. In line 33, the teacher again emphasizes the adverb, after a short pause, indicates the type, and gives the student an explicit positive assessment with a rising intonation. After a waiting time of 0.5 seconds, the teacher distributes the turn herself and gives a turn to $\mathrm{S} 3$ by saying her name.

35 T: Ö3 yap bakalım

\section{S3 do it}


38 S3: $\quad$ sabahleyin karşılaştığımız güne günaydın diyor do we say good morning your day in the morning muyuz? (.) sabahleyin

40 T: (.) in the morning eve:t (.) ne zaman günaydın diyor muyuz? (.) yes (.) when do we say good morning? sabahleyin (.) Ö4? in the morning (.) $S 4$ ?

At the beginning of the interaction, the teacher referred to the part in which S3 did not do the activities while she was taking her book, "She did it, wouldn't my dear ever do it?" says. Then, after the teacher shows that she can continue with the discourse marker, S3 reads the sentence and says the adverb in the sentence after a short pause. In line 40, the teacher confirms the answer with a discourse marker and repeats the sentence with the question to find the adverb. It is seen that the teacher gives a turn to $\mathrm{S} 4$ after repeating the adverb.

$43 \quad$ S4: $\quad$ 11: kişisel-kişisel gelişimle ilgili kitapları mmhm: pers-personal development books geçen yil okumuştum (.) geçen yı1 i read last year (.) last year

$45 \mathrm{~T}: \quad \underline{\text { ne zaman }} \uparrow$ okumuştum[? geçen y]11 when did I read $\uparrow$ [? last year

+başıyla onaylayarak

+nodded her head

46 S4:

[geçen yıl]

[last year]

$47 \mathrm{~T}$ :

a:ferin (.) Ö5?

very $\operatorname{good}($.$) S5?$

48 S5: insanlar bahar aylarında daha mutlu oluyor (.) people are happier in the spring bahar ayları in the spring 


\section{when are people happy?}

51 S5

bahar[aylarında

in the spring

$52 \mathrm{~T}$ :

[bahar aylarında (0.3) aferin

[in the spring (0.3) very good

+başıyla onaylayarak

+nodded her head

After a 0.5 second waiting time in line 42 , Ö4 reads the sentence and says the answer with emphasis after a short while. It is seen that the student repeats the answer before completing the question while the teacher says the question for finding the adverb in rising intonation in the 45th line. The teacher makes an explicit positive assessment by saying "well done" to the student's answer and maintaining the interaction. After the explicit positive assessment she gives to S4, the teacher turns S5 by saying his name. S5 reads the sentence in the 48th line, and after a short pause, he answers "spring months" in the 49th line. The teacher repeats the question to find the adverb in a rising intonation. It is seen that S5 started to repeat the answer to the question of the teacher, and the teacher confirmed this contribution of S5 both verbally (through repetition of the answer) and through body movements. After a short pause, the teacher continues the interaction by giving an explicit positive assessment.

53

54

55

56 S6:

57

Ö6?

\section{S6?}

$(0.6)$

sanatçı lise yıllarında uluslararası bir

The artist participated in an international competition

yarışmaya katılmış (.) lise yıllarında $\downarrow$

during her high school years (.)

During her high school years $\downarrow$

58 T: ne zaman yarışmaya katılmış

When did he/she participate in the competition?

+başıyla onaylayarak

+nodded her head 
li[se y1llarında (0.3)

\section{during her high school years}

60 S6: $\quad{ }^{\circ}$ [lise yıllarında ${ }^{\circ}$

${ }^{\circ}\left[\mathrm{d}\right.$ uring her high school years ${ }^{\circ}$

$61 \quad \mathrm{~T}: \quad(0.3)$ a:ferin

\section{(0.3) very good}

After a 0.5 second waiting time, she gives turn S6 by saying his name. After the waiting period of 0.6 seconds observed in line 55, S6 reads the sentence and, after a short pause, answers "in high school years" with a descending intonation. While the teacher emphasizes finding the adverb again, she confirms the student's answer with her head and repeats the answer. It is observed that S6 also repeats the teacher's repetition in a low voice in the overlap. After a short pause of 0.3 seconds, the teacher continues the interaction with the explicit positive assessment.

62

63

64

65 S7:

66

67

$68 x$

Ö7?

\section{S7?}

çoğu zaman en büyük pişmanlıklarımız

\section{most of the time our biggest regrets}

birbirimize söylediklerimizden kaynaklanır (.)

is caused by what we say to each other

[çoğu ]zaman

[most of] the time

[çoğu ] ((hangi öğrenci tarafından söylendiği anlaşılamadı))

[most of] ((could not understand which student said it))

69 T:

ne zaman $\uparrow$ kaynaklanır? (.) çoğu zaman $\uparrow$ (.)

\section{when is $\uparrow$ caused? (.) most of the time}

70

$$
\text { a:ferin }
$$

\section{very good}

After a waiting time of 0.9 seconds seen on line 62, the teacher gives turn S7 by saying his name. After a waiting time of 0.8 seconds, it is seen that S7 read the sentence. After a short waiting time, it is seen that while S7 was saying the answer, another student also spoke by saying "[most of]" but then fell silent. The teacher says the question to find the adverb with 
rising intonation and repeats the answer. In the 70th line, it is seen that the teacher made an explicit positive assessment, and in the 71st line, she emphasizes the transition to the next question with the discourse marker.

evet $\uparrow$ Ö8?

72 S8

Yes $\uparrow S 8 ?$ we will go to the conference on communication
gideceğiz (.) iki gün sonra
$74 \quad \mathrm{~T}: \quad$ ne zaman gideceğiz $\uparrow($.$) iki gün sonra \uparrow$ Ö9?
when will we go $\uparrow$ (.) two days later $\uparrow S 9$ ?
75 S9: $\quad$ bin dokuz yüz seksen sekiz bin dokuz yüz
between nineteen eighty eight nineteen
76 doksan sekiz yılları arasında üniversitede
ninety eight, $i$ worked as
77 öğretim görevlisi olarak çalıştım (.) $>$ bin
lecturer at the university
78
dokuz yüz seksen sekiz bin dokuz yüz doksan
nineteen eighty eight nineteen
79
sekiz $<$ yılları $\downarrow$
ninety eight $\downarrow$

8: $\quad$ iletişim konulu konferansa iki gün sonra

80 T:

yılları ara[sında (.) dimi?

Between the years (.) right?

81 S9:

[arasinda $\downarrow$

[between $\downarrow$

82 T:

ne zaman çalıştım (.) şu şu şu yıllar

when did $i$ (.) between bla bla bla years

83

arasinda $\uparrow$ arasindayı da alıyoruz (.) $>$ aferin $<$

we take between too (.) >very good<

84

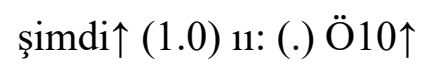

now $\uparrow(1.0)$ ul: (.) $S 10 \uparrow$

After giving the turn to S8 by saying his name, S8 reads the sentence and answers. It is seen that the teacher repeats the question of finding the adverb again after this contribution. Repeating the answer with a rising intonation, the teacher gives a turn to $\mathrm{S} 9$ by saying her 
name. After reading the sentence, S9 quickly answers as " $>$ nineteen eighty-eight thousand nine hundred ninety-eight $<$ years $\downarrow$ ". While getting the answer of S9, the teacher repeats the last part of the answer, "between the years (.)". S9 also adds the word "[between $\downarrow$ " to her answer, which she finished as "[between $\downarrow$ " in overlapping with the teacher's repetition. In line 80, the teacher makes the mistake of S9 implicitly; 82-83. lines are explicitly corrected. Then, the teacher who gives an explicit positive assessment ends the interaction and moves on to the next activity by turning another student with the phrase "now $\uparrow "$ on line 84 and emphasizing it. In the extract where teacher-student interaction is exemplified, it is seen that a grammar activity in the Turkish textbook is studied. In the interaction process in which this activity is done, the teacher distributes the turns, gives the students a waiting time to create their answers, confirms the student answers by repeating the teacher-student echo, uses body language and orientation, uses various elements to maintain order in the classroom, and explicit positive assessment elements.

\section{Extract2}

In Extract2, it is seen that the interaction example took place in one of the texts in the textbook. The text about Turkish coffee was being read in the activity; the teacher stopped the student and asked the information about Turkish coffee with a question whose answer is known. In line 2, she uses a rising intonation to attract students' attention. Meanwhile, S28 commented on the situation. The teacher confirms this comment on line 4 and completes the information she asked for (lines 4-9). In line 10, the student named S5 asks the teacher, "Well, but if they were poisonous, the goats would die, right?" answers the inference as "maybe it does not affect the goats". It is seen that the teacher, after confirming this answer with the discourse marker, conceptualized the student's answer and said, "that is, the shepherd who took a risk tried it himself (.)".

01 T: dur önce bir çoban kendi sürüsünde bunu fark ediyor dimi? (.) wait first, a shepherd notices this in her flock, right?

02 daha önce (.) daha önce $\uparrow$

before (.) before $\uparrow$

03 S28: onu fark etmesi de başarı ama

Realizing it is a success but...

04 T: evet çok önemli (.) daha önce kahve nedir bilen yok, yes very important (.) no one knows what coffee is before

05 dimi e bu çoban ee işte keçilerinin mi 11 bu otları-yaprakları uh this shepherd ee here is his goats these grass-leaves 
yediğini görüyo ve daha az uyanık 11-yok daha fazla uyanık he sees them eat and is less awake ii-no more awake kaldıklarını daha az uyuduklarını fark edip dinç olduklarını realize that they stay and sleep less görüyo ve kendisi de deniyo o da bi cesaret mesela zehirli bi he tried to it's also a dare, for example, it can be a şey olabilir ama zehirli olsalar keçiler ölürdü dimi? poisonous but goats would die if they were poisonous, right?

10 S5: belki keçileri etkilemiyor maybe it doesn't affect the goats

$11 \mathrm{~T}$ : evet beli dimi yani risk almış çoban kendi de denemiş bunu (.) Yes so the shepherd who took the risk and tried it himself and sonra yayılıyo bu şekilde it has known like this çekirdeklerini pişiriyolarmış dimi They were cooking their beans, right

14 S28: valla --- ((anlaşılamayan konuşma)) i swear --- ((inexplicable speech))

15 T: dimi? çekirdeklerini çekirdeklerini işte kırmızı çekirdekleri

16 alıp kurutarak sonra onları çekerek döverek öğüterek dimi (.)

17 kahve haline getirilmiş

right? The seeds, the seeds, here are the red beans He made into coffee by taking it, drying it, then grinding them by pulling and beating them right

11: bir sürü kahve çeşidi var günümüzde önceden Türk kahvesi>ama neden Türk kahvesi denmiş (.) bu da ilginç< there are many types of coffee nowadays formerly Turkish coffee- >but why is it called Turkish coffee (.), which is interesting $<$

In the 13th line, it is seen that the teacher passed on to another information about coffee. After elaborating the information about this feature between the lines13-17, she quickly completed the question. She asked why it is called Turkish coffee in the 18th line with her own repair on the 19th line. She comments on line 20, S11, "because it tastes more bitter" in response to this 
question. It is seen that the teacher left this comment unanswered and repeated her question by expanding it.

20 S11: çünkü tadı daha acı because it tastes bitter

21 T: $\quad$ yani Türkiye'de, şunu hiç düşündünüz mü, Türkiye'de I mean, in Turkey, have you ever thought about this,

22 yetiştirilmediği halde Türk kahvesi deniyo Even though it is not grown in Turkey, it is called Turkish coffee

23 S28: çok seviyoruz we love so much

24 T: acaba neden? Ö7? why? S7?

25 S7: hocam Osmanl my teacher ottoman empire

26 T: bi dakka (.) wait a minute

27 S7: o zaman osmanlı topraklarında Arap yarımadasından gelen bi

28 madde olduğu için ve orda yetiştiği için sonra saray getirilmiş 29 sonra Osmanlı (anlaşılmayan konuşma)

At that time, because it was a substance from the Arabian Peninsula in the Ottoman lands and it was grown there, then the palace was brought and then the Ottoman (incomprehensible speech)

30 T: tamam da neden Arap kahvesi denmemiş ok why not arabic coffee

The teacher did not accept the "we love it" answer from S28 in line 23 as the preferred answer was "I wonder why? S7?" It is seen that she repeats as "S7" and gives a turn to the student named S7 by saying his name (Mehan, 1979). Between lines 27-29, it is seen that S7 answered the question, but the teacher did not point this answer as the preferred answer (line 30). In the 31 st line, S27 shows that she is willing to answer by raising a finger (Kardaş-İssler, 2019) and saying, "I know my teacher (.), My teacher (.)", and the teacher gives a turn to her by saying her name after completing the question.

31 S27: hocam hocam (.) ben biliyorum \#parmak kaldırıp teacher teacher (.) I know \# raise your finger 
32 T: veya başka bi ülke denmemiş de Türk kahvesi denmiş? Ö27? or any other country, but Turkish coffee? S27?

33 hişşt (.) bi dakka çok önemli, shh (.) wait a minute this is important

35 S27: Türklerin

36 x: babası tarihçi ((hangi öğrenci tarafından söylendiği anlaşılamadı)) his father is a history teacher ((Could not understand which student said it))

37 T: $\operatorname{dur}($.$) Ö27 baba torpilli$ wait (.) S27 is lucky because of his father bi dakka just a moment

39 S27: hocam çünkü Türkler kahveyi alıp farklı bi şekilde pişirmiş teacher because the Turks bought the coffee and cooked it differently normal Araplar Lübnanlılar gibi değil farklı şekilde pişirmiş Cooked differently, not like Arabs or Lebanese dibinde telvesi bi şeyi kalmış o yüzden there were coffee grounds left that's why

$42 \mathrm{~T}: \quad$ hıh (.) güzel ve bunu törenle mi yapmışlar tören haline mi 43 getirmişler?

hih (.) good, and did they do it with a ceremony or make it a ceremony?

In line 33, it is seen that the teacher is trying to restore order (Burden, 2013) in the classroom. It is seen that after a waiting time of 6.3 seconds, S27 started to answer, but the teacher stopped again and maintained the classroom order. In line 36, another student pointed out that S27's father was a History teacher, and the teacher continued this comment in line 37. In line 38, the teacher draws attention again. Between lines 39-41, it can be seen that $\mathrm{S} 27$ has completed her answer. The teacher confirms by saying "huh (.) nice" and evaluates the answer with an explicit positive assessment. Immediately after this, the student shapes the answer with an additional question (shaping learner contribution, Can-Daşkın, 2015).

\section{Extract3}

$01 \quad \mathrm{~S} 11:$ ben yapiyim mi may $i$ do

$02 \mathrm{~T}$ : $\quad$ sekizinci soruya bakın $\uparrow$ peki Ö11 oku bakalım ne diyo 
03 S11: aşağıdaki cümlelerde pekiştirilmiş sözcüklerden hangisi zarf

04 görevinde kullanılmıştır?

Which of the reduplicated words in the following sentences is used as an adverb?

05 T: ha

06 S11: a sapasağlam vazoyu niye çöpe attın a why did you throw away the as sound as bell vase?

$07 \quad \mathrm{~T}: \quad$ dur (.) sapasağlam sözü sözcüğ̈̈ pekiştirilmiş bir sözcük mü? wait (.) is the word as sound as bell a reduplicated adjective?

08 S11: evet yes

$09 \mathrm{~T}$ : $\quad$ sapsağlam araya ünlü girmiş sapasağlam olmuş (.) düşebiliyodu sapsağlam vowel added between sap and sağlam also it could be haplology veya araya ünlü girebiliyodu bunu anlatmıştık (.) peki we explained that vowels could be inserted between them (.) ok zarf görevinde kullanılanı soruyo $\uparrow$ sapasağlam vazo demiş (.) it asks what is used as an adverb $\uparrow$ it says as sound as bell vase

12 S11: sifat adjective

13 T: $\quad$ sıfat dimi (.) nasıl vazo sapasağlam vazo adjective right (.) how vase as sound as bell vase

14 ismi etkilemiş sıfat görevinde as an adjective that influenced the noun

15 b ye bakalım let see $b$

16 S11: güpegündüz soymuşlar dükkanı robbed the shop in broad daylight

17 T: ha ha

18 S11: ne zaman soymuşlar (.) güpegündüz soymuşlar burda zarf when did they rob the shop in broad daylight here that is an adverb

19 T: $\quad$ zarf dimi (.)soymak fiildir (.) çekimli fiil (.) adverb right (.) the word rob is a verb (.) finite verb (.) 
ne zaman soymuşlar(.) güpegündüz (.) hangi zarf? (.) hangi tür when did they rob (.) in broad daylight which adverb (.) which kind of adverb

21 S11: zaman zarfi adverb of time

22 T: $\quad$ zaman zarfi adverb of time c ye bakalım yine let see c anyway

24 S11: dümdüz bi yol çıkmıştı karşımıza(.)dümdüz bi yol(.) a straight road view(.) a straight road (.) what kind of road nasıl bir yol (.) dümdüz bir yol (.) burda sifat what kind of road (.) a straight road (.) here that is an adjective

26 T: $\quad$ sifat (.) aferin adjective (.) very good

27 S11: masmavi gökyüzü huzur vermişti (.) nasıl gökyüzü (.) the deep blue sky gave peace (.) how sky (.) masmavi gökyüzü burda da sıfat deep blue sky that is an adjective to

29 T: a:ferin (.) ismi etkilediği için sıfat very good (.) adjective for referring the noun

Extract 3 begins with self-selected student initiation. After S11 asks permission to speak, the teacher draws the whole class's attention by using a rising intonation. Then she gives the turn to the student again by using the discourse marker. After the student read the instruction, she makes sure to continue by saying "ha". After stopping the student from reading the first option, the information polled in the instruction is given in the option "Is the word sapasağlam reduplicated word?" she asks. After receiving the yes answer from the student, she nods and explains the way of reinforcement of the word "sapasağlam" by referring to the past learning event (Can-Daşkın, 2017; Can-Daşkın, Hatipoğlu, 2019). After the explanation, she repeats the information requested in the instruction and the reinforced word in the sentence together with the word next to it, waiting for a response from the student. It also emphasizes the sound event that takes place in the word. The teacher emphasizes that the necessary examination for the information questioned through repetition requires the solid and vase to be considered together. After confirming the student's answer through repetition during the next speech, she 
repeats the question and the answer to find the answer. After the student's answer, the teacher repeats and confirms the answer, then uses the question adjective to indicate the function of the word and verbally guides the student to move on to the next option. After reading the option on the 16th line, the teacher, who allows the student to continue by saying "ha", confirms the student's answer again in the 19th line. In addition, the teacher indicates the type of word in which the word is used together to achieve the pedagogical goals of the lesson and repeats the question required to find the task. In line 20, the student answers "adverb of time" to the teacher, who asks the question again with self-initiated self-repair. After confirming this answer by repeating line 22 , the teacher gives verbal instructions to move on to the next option. Although the correct answer to the question is found in the verbal instruction, the teacher shows her willingness to examine the word in the other option by using "again". After the student reads the option and gives the answer, and confirms the answer through repetition, it provides a transition with an explicit positive assessment. The teacher, who reads the last option and then says the type of the word, gives a direct, explicit positive assessment in the last line and ends the student interaction with the question.

\section{Discussion and Conclusion}

In this study, the classroom interaction example in which the textbook, which is the only tool of most people in Turkey, is studied thanks to the micro-analytic perspective based on the data itself, which is recognized by the conversation analysis method. In this examination, it is seen that the Turkish teacher built the classroom culture on the question-answer interaction due to the repetitive nature of the activities. These interactions can occur as initiation-responsefeedback or evaluation interactions, and in this data example, they are usually dominated by the teacher. In the three sections discussed, the interactional resources used by the teacher in the lesson and for what purpose and how often they are used are listed in Table 2. It is seen that the activities in the textbook are covered in all three sections, and it is seen that the lesson teaching process is carried out similarly, although they have been done on different days and have different contents.

In language classes, it is observed that classroom interaction progresses as a set of tasks, and it is observed that these tasks affect the quantity and quality of speaking (Huth, 2011). It was stated that the teacher carried out the distribution of the turns in all three activities; It is seen that even in cases where students are willing to answer, their initiations remain at a certain limit. It can be observed that student contributions are repeated within certain patterns (Huth, 2011) and that the activities limit the interaction as question-answer 
interaction. The classroom interaction pattern of the activity examples in Turkish textbooks causes students to perceive all activities as questions, and therefore wait for the teacher to distribute the turns. In addition, it is thought that the teacher creates a classroom culture and the students dominate this formation in the way they form the order of conversation of the students (for example, students who take the floor after the emphatic positive evaluation in Extractl act with the knowledge that the use of the explicit positive assessment element indicates transition).

The teacher evaluates and confirms the students in the third turn in the question-answer activities, one of the most typical interaction elements of classroom interaction (Walsh, 2013). In addition, it is seen that the teacher does not only directly evaluate with verbal answers in the feedback/evaluation phase of these activities, which proceed in the form of questions and answers but also performs the process of "giving feedback" in multiple and different ways. The teacher (Whitehead, 2011), who uses body language in ways such as "reinforcing the meanings conveyed in speech, clarifying the dictionary meanings, maintaining harmony in long lines of conversation and preventing disconnection from the context" (Belhiah, 2013), is not limited to this when creating the evaluation series, for example, "hih" with the response (Girgin \& Brant, 2019). The teachers' use of more than one, a different form of giving consent and feedback provides acceleration in terms of continuity of interaction in the classroom, and the volunteerism of the students to answer shows that they are familiar with these uses. It can be said that this type of usage created during the third statement also points to the lack of feedback and makes it more difficult for students who do not understand to participate in the interaction than those who answered the question. It is seen that the teacher strives to shape and expand student contributions (Can-Daşkın, 2015), and often makes use of teacher-student sound reflection while arranging student responses. It confirms the students' answers by repeating and making sense of the correct forms and preferred answers by organizing or with these answers. The teacher performs implicit repair using teacher-student sound reflection.

The teacher also benefits from explicit positive assessment in the activity process; it uses it to both denote interaction closure (case closed, Batlle, 2021; Wong \& Waring, 2009) and transition (Batlle, 2021; Brophy, 1981). The literature states that the use of explicit positive assessment can prevent possible learning opportunities, so care should be taken when using these elements (Wong \& Waring, 2009). The teacher used these elements predominantly with the function of maintaining interaction in Extract1 and pointed out that the current question was passed. In Extract 3, she repeated the reason for the answer right after the explicit positive assessment, pointing out that the activity in question was closed and no further 
contribution was requested. From this point of view, it is seen that the teacher differentiates the use of explicit positive assessment elements within the teaching process. In addition, it is seen that the teacher also resorts to metalinguistic reference due to the nature of the Turkish lesson and tries to give students the rules and examples that she aims to make aware of in terms of grammar through activities and repetitions.

During language education, curriculum affects all parts of the process. While preparing the course materials, the authors of the books follow the framework in the curriculum, and the approach in the books shapes the teacher's practices in the course. However, the content and layout of the textbooks do not always allow for interactive lessons. The materials to be used in the course should be materials that can be used interactively efficiently (Seedhouse, 2005); It should be a curriculum for teachers, be in line with learning objectives and methods, and standardize education for all students while offering diverse and effective teaching opportunities (Richards, 2001). The textbooks used contain models with limited speaking features and do not allow real speaking practices (Pitaksuksan \& Sinwongsuwat, 2020). The quality of the materials used, in this example, the textbook, affects the teacher's teaching processes, causes the activities to remain at the question-answer border, and prevents the achievement of the interactive learning goal. This feature of the activities affects the participation of the students in the lesson. Since the questions that can be used in verbal communication are predominant in the activities, the question-answer interaction is limited only to the responding student and teacher, and other students are followers of the activity and cannot become a part of the interaction.

For example, the activity that constitutes the interaction process in Extract1 is included in the textbook (Figure 1). When we look at the example of the activity, it is seen that this activity has a measurement quality rather than a teaching process. Due to the nature of the activity, the teacher follows the textbook, constructs the interaction in the context of questionanswer, and evaluates the students based on their answers. It was observed that the teacher did not apply the activities in the books to increase teacher-student and student-student interactions by diversifying them (Figure1, Akgül, 2017). 


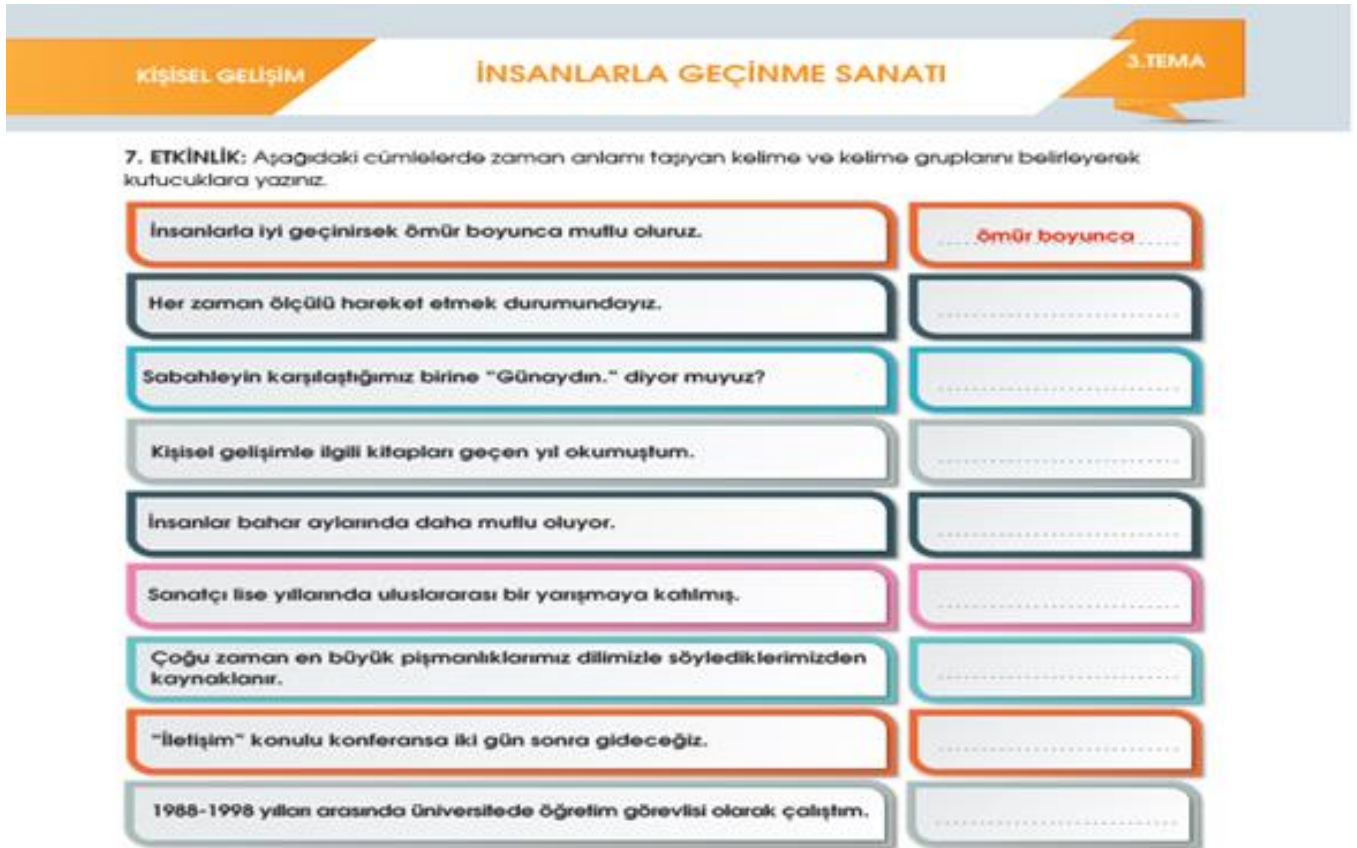

Figure 1. The activity that constitutes the interaction process in Extract1

A detailed examination of the interaction in the teaching process can be used for teachers to see the results of their own practice and make self-regulation. The data analyzed with the conversation analysis method will allow inferences not only for Turkish lesson teaching practices but also for teacher training. Sert and Seedhouse (2011) concluded that teacher candidates who see the effect of classroom interaction would affect their teachers' abilities in terms of interactional domain, shaping student contribution, giving effective feedback, correct use of teacher speeches, and interactional awareness.

Considering that the textbooks are the basic and most accessible course material, it is possible to look at the quality of the textbooks with practical teaching practices, with this and similar micro-analytical studies. The slightest positive change in the qualifications of the resources that reach millions of students will positively affect education. The targeted Turkish course curriculum may be a step in the preparation of resources that support an active learning process in which the targeted student is responsible for his learning.

The key aspect in the conversation analysis perspective is selecting the interactional sequence, and social actions that occur in all the lessons the researcher observes (Kääntä, 2021). In this data, teacher actions, teacher-student interactions show a definable social action feature. In addition, the data can be used to inform/raise awareness about the interactional aspects of the teacher's classroom practices through conversation analysis. 
Ethical Approval: This research was conducted with the permission of the Hacettepe University ethics committee with the decision no 35853172-044 dated 23.10. 2018.

Conflict Interest: There is no conflict of interest.

Authors' Contributions: The authors contributed equally to the study.

\section{References}

Akgül, A., Demirer, N., Gürcan, E., Karadaş, D., Karahan, İ. \& Uysal, A. (2019). Ortaokul ve imam hatip ortaokulu 7. sınıf Türkçe ders kitabı. Milli Eğitim Bakanlığı Yayınları.

Avcı, M. (2020). Vurgulu olumlu değerlendirmenin Türkçe dersleri sınıf içi etkileşiminde kullanımının incelenmesi. [Yayımlanmamış yüksek lisans tezi, Hacettepe Üniversitesi Eğitim Bilimleri Enstitüsü]. Hacettepe Üniversitesi.

Badem-Korkmaz, F., \& Balaman, U. (2020). Third position repair for resolving troubles in understanding teacher instructions. Linguistics and Education, 60, 1-13. https://doi.org/10.1016/j.linged.2020.100859

Batlle, J. (2021). "Muy bien" as a transition token in teacher-student interactions in the Spanish as a foreign language classroom. System, 97(2), 1-12 https://doi.org/10.1016/j.system.2020.102438

Belhiah, H. (2013). Using the hand to choreograph instruction: On the functional role of gesture in definition talk. The Modern Language Journal, 97(2), 417-434. https://doi.org/10.1111/j.1540-4781.2013.12012.x

Brophy, J. (1981). Teacher praise: A functional analysis. Review of Educational Research, 51(1), 5-32. https://doi.org/10.2307/1170249

Burden, P. (2013). Classroom management: creating a successful k-12 learning community. Wiley.

Can-Daşkın, N. (2015) Shaping learner contributions in an EFL classroom: Implications for L2 classroom interactional competence, Classroom Discourse, 6(1), 33-56. https://doi.org/10.1080/19463014.2014.911699

Can-Daşkın, N. (2017). A conversation analytic study of reference to a past learning event in L2 classroom interaction: implications for informal formative assessment [Doctoral dissertation thesis, ODTÜ SBE]. ODTÜ. 
Can-Daşkın, N., \& Hatipoğlu, Ç. (2019). Reference to a past learning event in teacher turns in an L2 instructional setting, Journal of Pragmatics, 142, 16-30. https://doi.org/10.1016/j.pragma.2018.12.023

Coulon, A. (2015). Etnometodoloji. Küre Yayınları.

Çakır, H. (2017). Türkçe derslerinde söylem belirleyicisi olarak ‘yani’nin işlevleri. H. Ülper (Ed.), Türkçe Eğitimi Güncel Araştırmaları içinde. Pegem Akademi Yayınları.

Çakır-Sarı, H. (2020). Türkçe öğretmenlerinin söylem belirleyicisi kullanımı. Dil Dergisi, 171(1), 75-90.

Çimenli, B., \& Sert, O. (2017), Orientations to linguistic form in meaning and fluency contexts in a Turkısh as a foreign language classroom. In G. Schwab, S. Hoffmann, \& A.Schön(Eds.), Interaktion im fremdsprachenunterricht: beiträge aus der empirischen forschung.Berlin.

Fagan, D. S. (2014). Beyond "excellent!": uncovering the systematicity behind positive feedback turn construction in ESL classrooms. Novitas-ROYAL(Research on Youth and Language), 8(1), 45-63.

Girgin, U., \& Brandt, A. (2019). Creating space for learning throuhg 'Mm hm' in a L2 classroom: Implications for L2 classroom interactional competence, Classroom Discourse, 11(1), 61-79. https://doi.org/10.1080/19463014.2019.1603115

Goffman, E. (2017). Etkileşim ritüelleri: Yüz yüze davranış üzerine denemeler. Heretik Yayınları.

Göğüş, B. (1983). Anadili eğitim programlarının niteliği. Türk Dili Dergisi Dil Öğretimi Özel Saylst, 379, 40-48.

Hellerman, J. (2003). The interactive work of prosody in the IRF exchange: Teacher repetition in feedback. Language in Society, 32(1), 79-104.

Heritage, J., \& Clayman, S. (2010). Conversation analysis: Some theoretical background. Talk in Interaction, Blackwell Publishing.

Huth, T. (2011). Conversation analysis and language classroom discourse. Language and Linguistics Compass 5(5), 297-309.

Kääntä, L. (2021). Multimodal perspective into teachers' definitional practices: Comparing subject-specific language in physics and history lessons.S. Kunitz, N. Markee \& O. Sert (Eds.), Classroom-based conversation analytic research: Theoretical and applied perspectives on pedagogy içinde. Springer Publishing. https://doi.org/10.1007/978-3030-52193-6_11 
Karatay, H., Dolunay, S.K., \& Savaş, Ö. (2014). Türkçe öğretmenlerinin etkin dinleme ve dönüt durumları. Ana Dili Eğitimi Dergisi, 2(4), 85-106.

Kardaş-İşler, N. (2019). İlkokul sosyal bilgiler dersinde öğrenci başlatımları ve ögrenme firsatları: Bir konuşma çözümlemesi çalışması. [Yayımlanmamış doktora tezi, Hacettepe Üniversitesi Eğitim Bilimleri Enstitüsü]. Hacettepe Üniversitesi.

Kimura, D.; Malabarba, T., \& Hall, J. K. (2018). Data collection considerations for classroom interaction research: A conversation analytic perspective. Classroom Discourse, 9(3), 185-204.

Kirsch, C., \& Seele, C. (2020). Translanguaging in early childhood education in Luxembourg: From practice to pedagogy. Inclusion, Education and Translanguaging içinde (ss.6381). Springer Publishing.

Lee Y. A. (2021). Taking teachers' ordering decisions in classroom interaction. S. Kunitz, N. Markee, \& O. Sert (Eds.), Classroom-based conversation analytic research: Theoretical and applied perspectives on pedagogy içinde. Springer Publishing. https://doi.org/10.1007/978-3-030-52193-6_11

Leslie, C. (2017). Group cohesion and learning opportunities in peer interaction. Porta Linguarum Monograph, 2, 245-265.

MEB (2006). İlköğretim Türkçe dersi (6, 7, 8. sınıflar) öğretim programı. MEB TTKB.

MEB (2019). Türkçe dersi ögretim programı (1, 2, 3, 4, 5, 6, 7 ve 8. sinıflar). MEB TTKB.

MEB. (2019). Ortaokul ve imam hatip ortaokulu 7. sınıf Türkçe ders kitabı. Milli Eğitim Bakanlığı Yayınları

Mehan, H. (1979). Learning lessons: Social organization in the classroom. Harvard University Press.

Onan, B. (2011). Anlama sürecinde Türkçenin yapısal işlevleri. Nobel Akademik Yayıncılık. Özbay, M. (2006). Türkçe özel ögrretim yöntemleri I. Ankara: Öncü Kitap.

Özcan, G., Aksan, Y (2017). Sözlü Türkçede evet'in görünümleri: Sözlü Türkçe derlemi’nden bulgular. Mersin Üniversitesi Dil ve Edebiyat Dergisi, 14(2), 15-35.

Pitaksuksan, N., \& Sinwongsuwat, K. (2020). CA-informed interactional feature analysis of conversations in textbooks used for teaching English speaking in Thai secondary schools. English Language Teaching, 13(7), 140-151. https://doi.org/10.5539/elt.v13n7p140

Richards, J. C. (2001). The role of textbooks in a language program. Cambridge University Press. 
Rowe, M. B. (1972). Wait-time and rewards as instructional variables, their influence on language, logic, and fate control: Part one - wait-time. Journal of Research in Science Teaching 11(2), 81-94.

Scales, P. (2015). Yaşam boyu öğrenme ve öğretim. Palme Yayıncıllk.

Seedhouse, P. (2005). Conversation analysis and language learning. Language Teaching, 38, 165-187.

Sert, O.; Balaman, U., Can-Daşkın, N., Büyükgüzel, S., \& Ergül, H. (2015). Konuşma çözümlemesi yöntemi. Dil ve Edebiyat Dergisi, 12(2), 1-43.

Sert, O. (2015). Social interaction and L2 classroom discourse. Edinburgh University Press.

Sert, O., Seedhouse, P. (2011). Introduction: conversation analysis in applied linguistics. Special Issue: Conversation Analysis in Educational and Applied Linguistics, NovitasROYAL (Research on Youth and Language), 5(1), 1-14.

Shi, J. (2015). Okay as an embodied backchannel in classroom interaction. ELT Voices, 5(5), $1-12$.

Sumruk, H. (2019). Yabancı dil olarak Türkçe öğretiminde etkileşim ve konuşma çözümlemesi yöntemiyle kelime öğretimi: A2 düzeyi, [Yayımlanmamış Yüksek Lisans Tezi, Türkiyat Araştırmaları Enstitüsü]. Hacettepe Üniversitesi.

Tainio, L., \& Slotte, A. (2017). Interactional organisation and pedagogic aims of reading aloud practices in L1 education. Nordic Journal of Literacy Research, 3, 61-82. https://doi.org/10.23865/njlr.v3.469

TÜBA Online Bilim Terimleri Sözlüğü, 03.08.2021, http://www.tubaterim.gov.tr/

Walsh, S. (2013). Classroom discourse and teacher development. Edinburgh University Press.

Waring, H. Z. (2008). Using explicit positive assessment in the language classroom: IRF, feedback, and learning opportunities. The Modern Language Journal, 92(4), 577-594. https://doi.org/10.1111/j.1540-4781.2008.00788.x

Whitehead, K. A. (2011). Some uses of head nods in "third position" in talk-in-interaction. Gesture, 11(2),103-122. https://doi.org/10.1075/gest.11.2.01whi

Wong, J., Waring, H.Z. (2009). 'Very good' as teacher response. ELT Journal, 63(3). 195203. 